\title{
Twenty-first Century Research Needs in Electrostatic Processes Applied to
}

\section{Industry and Medicine}

M. K. Mazumder ${ }^{1 *}$, R. A. Sims ${ }^{1}$, A. S. Biris ${ }^{1}$, P. K. Srirama ${ }^{1}$, D. Saini ${ }^{1}$, C. U. Yurteri ${ }^{2}$, S. Trigwell ${ }^{3}$, S. De ${ }^{1}$, and R. Sharma ${ }^{1}$

${ }^{1}$ Univ. of Arkansas at Little Rock, Department of Applied Science ETAS 575, 2801 S. Univ. Ave, Little Rock, AR 72204, Tel: 501-569-8007, Fax: 501-569-8020, Email: mkmazumder@ualr.edu ${ }^{2}$ Electrostatics \& Surface Physics Lab., Mail code: YA-C2-T, Kennedy Space Center, FL 32899 ${ }^{3} 205$ Particle Engineering Research Center, University of Florida, Gainesville, FL 32606

\subsection{ABSTRACT}

From the early $20^{\text {th }}$ century Nobel Prize winning (1923) experiments with charged oil droplets, resulting in the discovery of the elementary electronic charge by Robert Millikan, to the early $21^{\text {st }}$ century Nobel Prize (2002) awarded to John Fenn for his invention of electrospray ionization mass spectroscopy and its applications to proteomics, electrostatic processes have been successfully applied to many areas of industry and medicine. Generation, transport, deposition, separation, analysis, and control of charged particles involved in the four states of matter: solid, liquid, gas, and plasma are of interest in many industrial and biomedical processes. In this paper, we briefly discuss some of the applications and research needs involving charged particles in industrial and medical applications including: (1) Generation and deposition of unipolarly charged dry powder without the presence of ions or excessive ozone, (2) Control of tribocharging process for consistent and reliable charging, (3) Thin film $(<25 \mu \mathrm{m})$ powder coating and Powder coating on insulative surfaces, (4) Fluidization and dispersion of fine powders, (5) Mitigation of Mars dust, (6) Effect of particle charge on the lung deposition of inhaled medical aerosols, (7) Nanoparticle deposition, and (8) Plasma/Corona discharge 
processes. A brief discussion on the measurements of charged particles and suggestions for research needs are also included.

Keywords: - Electrostatic Processes, Charging Mechanisms, Powder Technology, Separations, Particulate, Polymers.

\subsection{INTRODUCTION}

Many industrial and biomedical processes involve powders and droplets; the electrostatic charges in these powders and droplets often play an important role in the process involved. The fundamentals of electrostatic charging, charge control, neutralization, deposition of charge particles, charge decay, charge measurements and control have been discussed in literature [Chang 1995; Cross, 1987; Hughes 1985; Mazumder 1998; Schein, 1998; White 1963;] that provide information on the role of electrostatics in many industrial and biomedical processes including (1) electrostatic precipitator, (2) powder coating, (3) ink jet devices, (4) laser printer and copying machines in electrophotography, (5) application of plasma discharge devices, (6) electrophoresis, (7) cell sorting, and (8) electrospray and proteomics. While the fundamental electrostatic processes involved in these and other applications have been addressed, there are still problems that remain to be solved. This article reviews some of these problems and possible solutions. The research needs are discussed with respect to the specific industrial and biomedical applications.

\subsection{CHARGING MECHANISMS}

The three mechanisms that are generally involved in charging materials are (1) corona charging, (2) induction charging, and (3) contact and tribocharging [White 1963]. We discuss here some of the problems related to these charging processes. 


\subsection{CORONA CHARGING}

Corona discharges are relatively low power electrical discharges that take place at or near atmospheric pressure [Cross 1987]. The corona is invariably generated by strong electric fields associated with small diameter wires and sharp edges of electrodes. Ions from a corona discharge can be used to charge particles or surfaces. For example, the photo-conducting surface of an optical photo conductor in a copying machine is charged by corona discharge. In a powder coating booth, a voltage of $-80 \mathrm{kV}$ to $100 \mathrm{kV}$ is applied to the powder-coating gun placed approximately $30 \mathrm{~cm}$ from the conducting substrate to be painted to sustain corona current. In powder coating or electrostatic precipitator applications, it is necessary to have a strong electric field near the collecting electrodes for efficient deposition of charged particles.

In the corona charging process, particles larger than $2 \mu \mathrm{m}$ in diameter are charged by field charging [White 1951] and particles smaller than $0.2 \mu \mathrm{m}$ are charged primarily by diffusion charging. The particles in the intermediate range are charged by both diffusion and field charging. For field charging, the particle charge can be derived from Pauthenier's (Cross 1987) equation expressed as

$$
\begin{aligned}
q(t) & =\frac{q_{s}\left(t / \tau_{c}\right)}{1+t / \tau_{c}} \quad(C) \\
\text { and } \quad q_{s} & =\frac{4 \pi r^{2} \varepsilon_{0} E\left(3 \varepsilon_{p}\right)}{\left(\varepsilon_{p}+2\right)} \quad \text { (C) }
\end{aligned}
$$

where $q_{s}$ is the saturation charge, $E$ is the electric field $(\mathrm{V} / \mathrm{m}), \varepsilon_{0}$ is the permittivity of free space, $\varepsilon_{p}$ is the dielectric constant of the particle, $r$ is the particle radius $(\mathrm{m}), \tau_{c}$ is the charging time constant (s), $t$ is the time in seconds. The charging time constant depends upon the concentration of ions or the ion current density, $\mathrm{J} \mathrm{A} / \mathrm{m}^{2}$ 


$$
\tau_{c}=\frac{4 \varepsilon_{o} E}{J} \quad(\sec )
$$

\subsubsection{Limitations in Corona Charging}

Corona charging is one of the most efficient charging processes and can be applied in a consistent manner to charge particles and droplets either positively or negatively within a relatively short period of time, usually less than 1 second. The corona charging process can be applied to both insulating and conducting particles in a wide size range of particles. However, there are some major problems: (1) corona charging is both a charging and deposition processes; the particles are charged and deposited in the same electric field that are required for charging the particles, thus making it very difficult to use it for charging of the particles alone. (2) Since the particles are charged by ions generated in the corona discharge process, and since less than $10 \%$ of the ions are used for charging particles, the remaining $90 \%$ of the free ions also deposit along with the charged particles, (3) When the resistivity of the particles is very high, the accumulation of electrostatic charge caused by the deposition of free ions leads to back corona resulting from the breakdown of the dielectric particle layer deposited on the conducting substrate.

\subsubsection{Ion Trap Corona Charging}

A corona charging system as depicted in Figure 1 was developed, consisting of a corona gun, a vibrating feeder, a powder pump, a spray chamber, an ion trap consisting of reciprocating grids with cleaning mechanism. A rotating substrate with deposition sites was added to demonstrate the application of the device for depositing charged powder in a desired pattern without depositing free ions. Two tests powders were used: (1) acrylic powder with a mass median diameter $\left(d_{50}\right)=27 \mu \mathrm{m}$, and (2) black toner with a mass median diameter $\left(d_{50}\right)=8 \mu \mathrm{m}$, to 
characterize the performance of the ion-free charger and the deposition chamber for depositing powder in an array. The results showed:

(1) Ion Trap: The free ion current was approximately $5 \%$ of the ion current measured without the reciprocating grids.

(2) High transfer efficiency: the first pass transfer efficiency (FPTE) was in the range of $70-80 \%$.

(3) Uniform powder deposition: the uniformity of deposition of powder on the substrate had relative standard deviation (RSD) of approximately $7 \%$ without any powder feed control.

(4) Compact size: the charging and deposition were performed in a single chamber, with cylindrical geometry, attached to a powder feeder and an exhaust system.

\subsubsection{Boxer Charger for Charging Polymer Powder without Free Ion Current}

The Boxer Charger (Fig 2.) [Grable 2001] developed by Masuda 1978, is a potentially ideal device for charging polymer powder without generating free ion current. However, it produces a large amount of ozone. The Boxer Charger was able to charge epoxy powder consistently (RSD $<3 \%$ ) to within $53 \%$ of the Pauthenier limit for negative polarity and within $44 \%$ of the Pauthenier limit for positive polarity. Equation 2 gives the Pauthenier Limit. Introducing sheath air into the Charging Unit eliminated the powder deposition on the walls and improved the average transfer efficiency from about $60 \%$ to greater than $80 \%$. The net charging efficiency was affected by a tribocharging component, which was a function of transport hose material, length and bends. An ozone trap inserted after the Charging Unit reduced ozone emissions to less than the OSHA 8-hour maximum Permissible Exposure Level (PEL) of $0.1 \mathrm{ppm}$. 


\subsubsection{RESEARCH NEEDS IN CORONA CHARGING PPROCESSES}

A. Development of a corona charger that can be used for particles in wide size ranges with varying charge-to-mass $(\mathrm{Q} / \mathrm{M})$ ratio, with the goal that the powders can be charged from $10 \%$ of their maximum charge to nearly $100 \%$ of their saturation charge level.

B. The charging of powder must be unipolar, but a single device should be suitable for charging powders both positively or negatively with a minimal change over time so that the same device can be used to charge the powder flowing through the device from the positive to the negative saturation levels by using an appropriate high voltage control and switching mechanisms.

C. The charged powder coming out of the device should not contain any appreciable amount of free ions. The corona charger should incorporate an ion trap that collects ions but doesn't accumulate charged or uncharged powder.

\subsection{Diffusion CHARging}

While field charging is the dominant charging mechanism for particles larger than $2 \mu \mathrm{m}$ in diameter, diffusion charging [White 1951] becomes important for particles smaller than $0.2 \mu \mathrm{m}$ in diameter. It is independent of the electric field $\mathrm{E}$.

If a particle is exposed to an ion concentration $\mathrm{N}_{0}\left(\mathrm{ions} / \mathrm{m}^{3}\right.$ ), it will acquire in time $t$ the charge $q(t)$ given by

$$
q(t)=\frac{4 \pi \varepsilon_{0} r k T}{e} \ln \left(\frac{r N_{0} e^{2} u t}{4 \varepsilon k t}+1\right) \quad(C)
$$

where $r$ is the particle radius, $k$ is Boltzmann's constant, $T$ is the absolute temperature in Kelvin, $e$ is the elementary charge, and $u$ is the mean thermal speed of ions (approximately $240 \mathrm{~m} / \mathrm{s}$ ).

Diffusion charging is limited to fine particles; the final charge-to-mass ratio of the particles charged by diffusion depends upon the particle radius and the product of the concentration of the 
ions $(\mathrm{N})$ and the charging time period $(\mathrm{t})$. While diffusion charging is a slow process, it can be used to charge fine particles to a relatively low charge-to-mass ratio needed for depositing fine powder with a minimal problem arising from back corona.

\subsubsection{Research Needs for Diffusion Charging}

A. Methods for diffusion charging of particles from nanometer size to $10 \mu \mathrm{m}$ in diameter needs to be developed for electrostatic applications of ultrafine and fine particulate matters.

B. Methods for generating unipolar ions without producing excess amount of ozone needs to be developed for diffusion charging of particles, either with positive or negative polarity.

\subsection{INDUCTION CHARGING}

In an electrospray process, the droplets are charged by induction charging. If the droplets consist of a liquid which evaporate rapidly, then, the charged droplets will evaporate until the Rayliegh limit is reached. The droplets then disrupt to smaller droplets. The process produces a fine mist of highly charged droplets. For a suspension undergoing the electrospray the evaporation and electrostatic atomization result in a cloud of fine particles. For example, induction charging is used in continuous ink-jet printing, where ink droplets are charged and deposited in the printing process. Charge acquired during the induction charging [Cho 1964, Atten 1992] process by a conducting sphere is given by,

$$
q_{p}=4 \pi \varepsilon_{0}\left(1.64 E_{0} r^{2}\right) \quad(C)
$$

For a dielectric sphere, the charging time constant $\tau$ is given by charge decay time constant of the particles,

$$
\tau=\varepsilon_{0} \varepsilon_{p} \rho_{r} \quad(s e c)
$$

where $\varepsilon_{p}$ is the dielectric constant of the particles, $\varepsilon_{0}$ is the permittivity of free space and $\rho_{r}$ is the resistivity of the particles. For dielectric spheres charging is a slow process and therefore 
induction charging is primarily applicable to conducting and semiconducting particles (or droplets).

The maximum charge on a droplet is limited by the Rayliegh limit [Cross 1987, 1998; Hendricks 1963]

$$
q_{\max }=\left(64 \pi^{2} \varepsilon_{0} \gamma r^{3}\right)^{1 / 2} \quad(C)
$$

where $\gamma$ is the surface tension of the droplet. The maximum charge-to-mass ratio,

$$
(q / m)_{\max }=\left(36 \varepsilon_{0} \gamma / r^{3} \rho_{p}\right)^{1 / 2} \quad(C / K g)
$$

where $\rho_{p}$ is the density of the liquid droplet.

For depositing nanoparticles on a substrate by atomizing a suspension of nanoparticles in a volatile liquid or for electrospray ionization mass spectroscopy as applied to identifying proteins, the diameter of the spray nozzle needs to be small, often in the range of a few micrometers. The nozzle must be made of materials that do not react or corrode in the liquid being sprayed. Operating multiple nozzles continuously (without clogging) for controlled deposition of nanoparticles on substrates is a formidable problem.

\subsubsection{Spinning Disk Charger}

To study the effect of electrostatic charge distribution in transport and delivery, it is often necessary to produce particles of known size and charge distribution. A spinning aerosol generator (Figure 3) can be used to produce fairly mono-disperse particles with a controlled electrostatic charge distribution, which can be either unipolar or bipolar. The particle size can be varied from 1-10 $\mu \mathrm{m}$ in diameter. The aerosol produced by the spinning disk generator is used to study the deposition of the particles in the different sections in the human lung model. The aerosol concentration at different levels is measured by using an ESPART analyzer. 


\subsubsection{Research Needs for Induction Charging}

A. Spinning cups used as spray guns for applying water-based paints need improved design to minimize the electrostatic hazards in operation and to control the distribution of the droplet size for enhanced deposition efficiency.

B. Convenient methods for spraying solution or suspension for creating mists of ultrafine or fine charged powder clouds are needed for their applications to wide ranges of industrial and medical applications, such as using metal or metal oxide nanoparticles in fuel cells, surface catalysis in gas-to-liquid conversion of natural gases, and reduction of nitrogen oxides in flue gas cleaning.

C. Electrostatic deposition of nanoparticles, including carbon nanotubes, to form a desired pattern, such as for making electrical connections using microelectrostatic field control, is needed.

\subsection{Charge Neutralization}

For its importance in semiconductor electronics, electrostatic discharge (ESD) process has been studied for many years. ESD control is an essential element in the manufacture of microelectronics. Diffusion is used for neutralization of electrostatic charge on semiconductor chips using bipolar ions of high concentration. Bipolar ions are produced using an $\mathrm{AC}$ corona discharge device by an ac voltage, usually $5 \mathrm{kV}$ at a frequency of $60 \mathrm{~Hz}$ [Chang 1995]. Another

method of generating bipolar ions uses radioactive sources such as Krypton-85 $\left({ }^{85} \mathrm{Kr}\right)$ and polonium-210 $\left({ }^{210} \mathrm{Po}\right)$. Radioactive sources generate bipolar ions, which can neutralize charged particles or surfaces. An advantage of radioactive sources is that no high voltage is necessary; hence they can be used where electrostatic sparks would be a serious hazard. 


\subsubsection{Research Needs in Charge Neutralization}

A portable lightweight ion generator needs to be developed for convenient application of charge neutralization that would be both inexpensive and electrostatic hazard-free. In typical applications, either a radioactive source or a high voltage corona discharge process is used; these are neither convenient nor inexpensive. Methods of generating high voltage, low current sources for production of bipolar ions using electromechanical means such as piezoelectric crystals. One application of such a portable ionizer would be to minimize the excessive electrostatic charges on the particles used as medical aerosols that are inhaled for their deposition in different sites of human lungs. Many devices used for generating medical aerosols, such as metered dose inhalers (MDI) and dry powder inhalers (DPI) often generate charged particles.

\subsection{TRIBO CHARGING}

Tribocharging occurs through two mechanisms: (1) contact charging, and (2) friction charging. In both cases, the mechanical processes that produce the charging of materials are: (a) sliding, (b) rolling or milling, (c) impact, (d) vibration of the surface at contact, (e) separation of solidsolid, solid-liquid, and liquid-liquid surfaces, and (f) deformation leading to charge distribution at stress points. The amount of triboelectric charge exchanged between two contacting surfaces depends upon their relative speed, the difference in work function, and on the pressure between the surfaces in contact. As the pressure increases, the area or the number of contact points increases. The surface charge density achieved by this process can be very high.

\subsubsection{Correlation between surface chemistry and tribocharging of powders}

The amount and polarity of charge transferred between two dissimilar materials, such as metals and polymer powders, was determined to be controlled partly by the surface chemistry [Trigwell 2003a; Sharma 2004]. The principle component in the surface chemistry was the effect of 
surface composition, i.e. contamination and oxidation, on the change in the surface work function. The work functions of various materials were measured by Ultra-violet photoelectron spectroscopy in air, and are shown in Figure 4. The surface composition of the same materials was determined by X-ray photoelectron spectroscopy, as shown in Table 1. It was observed that the metals tended to show a smaller work function increase for higher levels of surface contamination, whereas the polymers showed that only a small deviation in surface composition appeared to cause large increases in the work function.

This may be due to the difference in how the surfaces react with the environment. The composition on the metal surfaces was predominantly physisorption of hydrocarbon contamination with various amounts of alcohol or ester $(\mathrm{C}-\mathrm{O})$, ketone or aldehyde $(\mathrm{C}=\mathrm{O})$, and carboxylic acid or ester (COO) groups, whereas for the polymer surfaces, the XPS data indicated the surface functional groups showed reactive (oxidation) interaction with the environment. Tribocharging data using epoxy and acrylic powders passed through static mixers was obtained. Using the measured work functions for acrylic powder, and the static mixer materials, aluminum, copper, stainless steel, and polycarbonate, a plot of the net charge against the measured work function difference was calculated and shown in Figure 5. The error bars for the epoxy powder were larger as the work function was estimated. For both powders, particularly for the acrylic, there exists a distinct linear correlation between the net amount of charge obtained by each powder, and the work function difference between the powder and the charging material. In almost all cases, the measured work function was higher than the work functions reported in the literature from measurements made in high vacuum conditions. Figure 4 shows the measured work function under ambient condition and the experimental data reported in the literature from the measurements under high vacuum with atomically clean surface. Therefore, it will be 
necessary to control the composition of surface chemistry, which is often influenced by physisorption and chemisorption of atmospheric gases and vapors on the surface of the powder. One method of cleaning the surface and treating the surface with a layer of adsorbed gases would be to use plasma treatment, which is described later in this report.

\subsubsection{Tribocharging Research Needs}

A. Tribochargers are needed, with their primary applications to powder coating and electrophotography, that can be used to control both the polarity and magnitude of electrostatic charge of powders with the following characteristics:

1. Unipolar charging of powder, either positive or negative

2. Reliable operation of the charger, where the charging process does not change significantly as a function of time or ambient conditions, such as variation of relative humidity within a certain acceptable range

3. Application of fine particles, in the range of $1-25 \mu \mathrm{m}$ in diameter for powder mass flow rate ranging from only a few grams per minute to several kilograms per minute

4. A self-cleaning tribocharger with minimal contamination from the deposition of powder on the surface to ensure prolonged operation of the charger and to minimize the fatigue problem encountered in high speed copying machines

Fundamental research is therefore needed to treat the powder surface for both decontamination and to make the surface hydrophilic so that the moisture adsorption is minimized. For tribocharging fine powder, it will be necessary to use the milling process where the fine powders in the size range from 1-30 $\mu \mathrm{m}$ in diameter is mixed with another coarse powder in the range of 80-150 $\mu \mathrm{m}$ in diameter in such a manner that the mixing process will provide the charging followed by a process of separation for the removal of fine powders for the intended application. 
While the milling process is well-adapted in electrophotography, an industrial-scale charging device is needed to charge fine powder either by using a fluidized bed with the two powders mixed as an ordered mixture, or by using several small diameter static mixer-type tribochargers connected in parallel that will have high tribocharging for fine particles. Such a tribocharger must have appropriate self-cleaning features.

\section{MEASUREMENTS OF ELECTROSTATIC CHARGE ON PARTICLES}

\subsection{Charge Separation and Bulk Q/M Measurements}

The charge separator [Mountain 2001, Srirama 2003] (Fig 6) is an instrument that separates the particles based on their charge polarity. It consists of two V-shaped conductive plates with a variable voltage applied in between. The positively charged particles will be collected on the negative plate, while the negatively charged particles are attracted to the positive plate.

As the particles move downward inside the separator, the particles with very low charge, or those which are completely uncharged are collected on a filter paper at the bottom of the separator. If the two plates of the separator are connected to electrometers the accumulated charge $(\mathrm{Q})$ can be measured. Similarly, by weighing the plate before and after deposition, the mass (M) of the collected particles can be measured. Thus, the charge-to-mass ratios $(\mathrm{Q} / \mathrm{M})$ of the positively and negatively charged mass fractions are determined.

\subsection{Simultaneous measurement of PARTiCle Size AND EleCtrostatic Charge}

\section{DISTRIBUTION BY ESPART ANALYZER}

The ESPART analyzer [Baron 2001] has been used in the toner industry for many years for measuring the charge distribution of toner particles. Its principles of operation, performance characteristics have been well documented in literature. In an ESPART analyzer, the measurements are performed by oscillating the particles in an acoustic or electric field or by 
simultaneous application of both acoustic and electric fields. The motion of the particle is measured in real time through the application of a Laser Doppler Velocimetery (LDV) or by using image analysis as shown in Figure 7. One of the characteristics of the ESPART analyzer is that the range of the particle size depends upon the frequency of excitation (either acoustic or electric). The range of particle size covered by the instrument at different drive frequency is shown in Figure 8. In the toner industry, the ESPART is used at a drive frequency of $1 \mathrm{kHz}$. However, in order to cover a much wider range of particle size it is necessary to drive the particles at multiple frequencies. A digitally controlled ESPART analyzer where the drive frequency can be varied depending upon the particle size and electrostatic charge distributions which employs both acoustic and $\mathrm{AC}$ electric drive; making it possible to cover particle size for 0.5-50 $\mu \mathrm{m}$ and the electrostatic charge from zero to the saturation charge is presently being developed.

\subsection{E-SPART Analyzer Needs for Research}

A. For its application to several industrial and medical processes, the E-SPART analyzer should be improved to have the following features:

1. Wide size range: For a given drive frequency, the size range is narrow for accurate measurements. Therefore, it is necessary to operate the E-SPART analyzer in multiple frequencies so that a wide range of particle sizes can be covered for measuring both aerodynamic diameter and electrostatic charge for individual particles simultaneously. It is also necessary to have the relaxation chamber of the instrument designed for sampling aerosols either vertically downward or vertically upward to adjust the residence time of the large particle inside the sensing volume. 
2. Nanoparticle application: Research is needed to measure the particle size and electrostatic charge for particles in the nanometer range. For extending the range to the nanoparticle, it will be necessary to have a sampling system where all the extraneous particulate contaminates, such as atmospheric fine aerosols, are removed. Measurements will have to be performed with a high-intensity laser doppler velocimeter with a small sensing volume, a low-noise photon detector, and an advanced data acquisition system. Application of high frequency electric drive is needed, possibly in the range of $100 \mathrm{kHz}$ or higher, for driving the fine particles for determining the phase lag and amplitude of particle motion in an AC field.

3. Accuracy of charge measurement: The particle charge must be measured in a wide range, from positive to negative saturation charge, with a sampling system that will allow highly charged particles to enter into the sensing volume. The electrical drive should be such that the $\mathrm{AC}$ drive amplitude is automatically adjusted to accommodate the oscillating motion of the particle within the boundaries of the sensing volume of the E-SPART analyzer. The overall accuracy of both size and charge measurement must be high for this application in fundamental research in both industry as well as for biological particles.

4. Compactness: The size of the analyzer should be reduced for in-line operation.

\subsection{ELECTROSTATIC APPLICATIONS AND CURRENT RESEARCH NEEDS}

\subsection{ELECTROPHOTOGRAPHY: COPYING MACHINES AND LASER PRINTERS}

About the same time electrostatic precipitators became widely used in industry for removing particulate material from gas, a new application of electrostatics emerged - electrophotography. Electrophotography [Schein 1988], used in office copiers and laser printers, is by far the most successful application of all electrostatic engineering processes. Electrophotography is similar to optical photography. The process uses a photoconducting surface, where electrostatic charges are 
uniformly deposited by corona discharge for storing a latent image. The development of the image involves tribocharging of toner particles against carrier beads in a two-component development. Both corona and tribocharging processes are involved in electrophotography, and control of the charging process is essential for ensuring high performance copying and laser printing

Some of the current challenges in electrophotography include the use of small-size toner with diameter close to $4 \mu \mathrm{m}$ and within a narrow size range. Use of fine toner particles, often called micro-toner, has some engineering problems: (1) the fine particles are cohesive and the dispersion of toner particles require an extensive use of surface additives to maintain uniform flow of toner materials, and (2) these fine particles have a high charge-to-mass ratio, therefore, the mass transfer of toner from the carrier during the development of the image involves a higher adhesion force between the toner and the carrier and a relatively smaller electrostatic force for the transfer of the individual toner particles to the photoconducting drum.

\subsection{ELECTROSTATIC SEPARATION}

Triboelectric separation of coal from minerals, quartz from feldspar, phosphate rock form silica sand, rubber from fabric, zircon from rutile, phosphorus and silica from iron ore, and diamond from gangue has been successfully demonstrated in laboratory experiments, pilot plant studies, and, in some cases, commercial plants [Gidaspow 1987; Ralston 1961]. Electrostatic separation is achieved by exploiting differences in the resistivities of the materials or their tribocharging characteristics.

In one method of electrostatic beneficiation, pulverized coal is tribocharged by contact with electrically grounded copper. Coal maceral and mineral particles charge with positive and negative polarities, respectively. The charged particles are passed through a separator (Figure 9) 
consisting of two plate electrodes, across which a high voltage is applied, and the positively charged coal particles are separated from the negatively charged minerals. The efficiency of separation is dependent upon coal bulk and surface composition, and fineness of grind. Analyses of total sulfur and ash content of the charge-separated particles were used to evaluate beneficiation success of the Illinois no. 6 and Pittsburgh no. 8 coals studied. Two-stage beneficiation (Figure 10) [Trigwell 2003b] demonstrated improved separation. Historically, electrostatic beneficiation of minerals from coal has been a subject of investigation. It is based on the premise that coal macerals and pyrite inclusions will charge with opposite polarity when tribocharged against copper, hence allowing easy separation in a charge separator.

\subsubsection{Electrostatic Separation Process Research Needs}

The major problem in electrostatic separation is in the process of charging the particles with desired polarities. Surface contamination of the particles is the major obstacle. If the particulate separations are performed based on the difference in their electrical resistivity, it is necessary that the powders to be separated have a wide difference in electrical resistivity as well a wide difference in adhesion forces between the separation plate and the powders to be separated.

\subsection{ELECTROSPRAY AND NANOPARTIClE DEPOSITION}

Electrostatic Microencapsulation: Deposition of nanoparticles on the surface of catalyst has been successfully applied in many electrochemical processes involved in energy and environmental science applications. Fine particles of $\mathrm{Ni}, \mathrm{Cd}, \mathrm{Md}, \mathrm{W}, \mathrm{Pd}$, and $\mathrm{Ti}$ have shown to enhance the reaction rate involving catalyst in processes like conversion of methane to a more useful fuel, reduction of $\mathrm{NO}_{\mathrm{X}}$, and minimization of corrosion of aluminum surface. In order to deposit fine powder on the surface of larger carrier particles such as ceramic catalyst powder, an electrostatic microencapsulation tower [De 2002b] has been designed and tested. In this process, 
as shown in Figure 11, the larger carrier particles are charged with one polarity whereas the fine particles either generated by an electrospray process or by an exploding wire technique are mixed within an electrostatic coagulation reactor to produce microencapsulated carrier particles. The process can also be used for generating composite powder where particles of different composition can be mixed to form an ordered mixture.

Corona Deposition: Metal nanoparticles have found a number of applications in nanoelectronics, fuel cells, corrosion and biological systems. Nanoparticles have an extremely large surface area, a single crystalline structure, and have many applications. Metal nanoparticles (especially gold) are of interest in nanomaterial science and have recently been used to build nanowires and for making electronic transistors [Biris 2003b; Magnusson 1999]. Layers of noncorrosive nanoparticles deposited on metallic substrates can potentially inhibit or considerably reduce corrosion rates. A point-to-plane corona discharge setup was used for the ion bombardment experiment in air at atmospheric pressure. The corona tip was made of a high purity (>99.9999\%) $5 \mathrm{~mm}$ diameter gold wire, sharpened at one end while the other end was connected to a negative power supply and the voltage was increased until a stable corona discharge was observed between the gold electrode and the grounded substrate. Using the setup is shown in Figure 12, it was possible to produce gold nanoparticles with diameters varying from 20 to $450 \mathrm{~nm}$. The diameters of the gold nanoparticles increased as the electrical field intensity increased. AFM and SEM/EDX studies have shown the relationship (Figure 13) between the size distribution of the gold and tungsten nanoparticles and the electrical field intensity $\mathrm{E}$.

\subsubsection{Electrospray and Nanoparticle Deposition Research Needs}

Fundamental studies in charging nanoparticles and their deposition properties need to be conducted for nanopowders of different electrical resistivities. Since corona or tribocharging cannot be conveniently used for charging nanoparticles without the corresponding wall losses, 
the most appropriate devices would be to employ electrospray with ultrafine nozzles, use a highspeed spinning disk charger, or use the diffusion charging process.

\subsection{Mitigation OF MARS DUST}

Significant amounts of dust clouds are present in the atmosphere of Mars. Early spacecraft missions confirmed hypotheses from telescopic work that changes observed in the planet's surface markings are caused by wind-driven redistribution of dust. In these dust storms, particles with a wide range of diameters $(<1 \mu \mathrm{m}$ to $50 \mu \mathrm{m})$ are a serious problem to solar cells, spacecraft, and spacesuits [Landis 1996]. To analyze the size and charge distribution of the Mars dust cloud, a miniature version of ESPART analyzer $(20 \mathrm{~cm} \times 20 \mathrm{~cm} \times 20 \mathrm{~cm})$ is being developed, to be tested under a simulated Martian atmosphere (pressure $10 \mathrm{mb}$, with Martian dust simulant). To mitigate dust from depositing on solar panel, an electrodynamic screen is being developed, as shown in Figure 14, following the pioneering work by Masuda 1998 and Moesner 1997.

\subsection{EFFeCt OF PARTICle SIZE \& CHARge ON THE LUNG DEPOSITION OF INHALED AEROSOL}

Respirable drugs are widely used for treating lung disease such as asthma, emphysema and cystic fibrosis. Localized delivery of drugs to the respiratory tract has become an increasingly important and effective therapeutic method [Bailey 1998]. A small quantity of fine powder often in the form of an ordered mixture between large carrier particles in the range of $20-30 \mu \mathrm{m}$ in diameter and the drug particles in the size range of 1-7 $\mu \mathrm{m}$ in diameter, is used for each use. These powders are dispersed during the inhalation process and the fine drug powders get separated from the carrier particles with the objective that these fine particles can deposit in the distal airways and in the alveolar region of the lung for their effective use. The deposition of these inhaled therapeutic aerosol particles in the lung depends on the particle size, charge 
distribution, particulate number density, breathing rate, and the aerodynamics of the lung. [Balachandran 1997]. A glass bead lung model [Saini 2002] has been developed (Figure 15) to study the site-specific deposition as function of size and charge of the drug particles. The experimental setup includes the surrogate lung, an anatomical throat section, spinning disc aerosol generators, flow control system, and an ESPART analyzer. These respiratory drugs are inhaled from dry powder inhalers (DPI), metered dose inhalers (MDI), spinning disk aerosol generators, atomizers or nebulizers.

The experimental data showed that the fine particles are highly charged in many cases and it is possible that the high electrostatic charge may hinder the deposition efficiency in the desired region of the lung. In order to simulate the inhalation process and study the effect of the ambient relative humidity and the effect of breathing pattern, both the sampling process (Figure 16) and the surrogate lung model are used to study: (1) dispersion and charging characteristics of DPI and MDI aerosols, and (2) the deposition in the lung model as a function of Particle Size Distribution (PSD) and Charge to Mass Distribution (Q/M)D of particles.

\subsubsection{Research Needs in Lung Deposition of Inhaled Particles}

A. Charging mechanisms: The fundamental processes that are involved in charging of the particles in the generation of medical aerosols needs to be studied for both MDI and DPI aerosols.

B. Effect of the charge distribution: The particle size and electrostatic charge distributions that will produce enhanced deposition at the desired sites of lung when those particles are inhaled needs to be studied.

C. Agglomeration and wall loss: To improve the efficiency of drug delivery, the magnitude, polarity, and concentration need to be controlled. Electrostatic charge with a symmetrical 
bipolar distribution for the aerosol cloud provides a minimal space charge field during transport of drug particles through the preliminary tree. The individual particles should have a sufficient amount of charge for enhanced deposition.

D. Hygroscopic growth: Since the inhalation and deposition of aerosol is a dynamic process, further research work is needed for drug delivery so that the initial particle size and electrostatic charge distribution are controlled, ensuring they reach the desired target area in the lung, while undergoing coagulation and growth expected due to high particulate concentration and a highly humid environment.

\subsection{POWDER COATING}

Powder coating [Hughes 1985] is a multidisciplinary field of: (1) polymer science, (2) powder manufacturing, (3) fluidization and transport of powder, (4) particle charging and dispersion, (5) electrostatic spraying and coating, (6) curing and melt rheology, and (7) process modeling and optimization. Electrostatic powder coating is an environmentally safe, economically competitive, high-quality painting process for metals and plastics. The oversprayed powder can be recycled back into the coating process to achieve better than $95 \%$ material utilization. This high-efficiency application contrasts dramatically with solvent based coating, which creates serious environmental and energy related problems.

The current challenges in powder coating includes: (1) deposition of charged powder on the substrate without the presence of free ions and thus minimizing the problems that arises from back corona, (2) improved Faraday penetration [De 2003] of the charged powder into the parts of the workpiece with recesses, (3) development of a process for applying thin film, (4) deposition of charged powder on non-conducting substrates such as wood, (5) coating of large surface areas such as an aircraft, (6) variation of charging levels and inconsistent operation of tribocharging 
guns, and (7) excessive time required for color changes. Fluidization, uniform powder flow, and charging of fine powders to a desired value of $\mathrm{Q} / \mathrm{M}$ are some of the fundamental barriers in thin film $(<15 \mu \mathrm{m})$ powder coating [Biris 2001, De 2002a]. Applications of fine powders are needed for aircraft coating with UV curing and for scratch resistant coating.

\subsubsection{REDUCTION OF FREE IONS BY USING A RING ELECTRODE ATTACHED TO A CORONA GUN}

In order to reduce the number of free ions depositing on the powder layer and therefore reducing back corona, two ion-robbing ring electrodes were designed and studied [Biris 2003a]. The acrylic powder used in the experiments had a particle size distribution (PSD) of $\mathrm{d}_{10}=17.8, \mathrm{~d}_{50}=$ 27.3 and $\mathrm{d}_{90}=42.9 \mu \mathrm{m}$, and was fluidized in a Nordson fluidizing bed for 20 minutes before each experimental run. The first ring had a smooth surface and the second ring had 11 sharp points for concentrating electric field lines.

The experiments were conducted at voltages, $-60,-80$, and $-100 \mathrm{kV}$. Using Lorentz 2D simulation software, the electrical field lines were plotted for different applied voltages and for various geometries of the grounded ring electrodes. The simulations of the electrical field lines with and without the ion robber rings as well as the schematic of a corona gun with ring electrode are shown in Figure 17. The electrical field is strongest near the corona electrode and weakest at the grounded target.

Adding the sharp points to the ring electrode was found to provide self-cleaning properties of the ring electrode. By increasing the distance from the ring electrodes to the corona gun electrode, or by increasing the powder flow rate, it was possible to control the amount of $\mathrm{Q} / \mathrm{M}$ acquired by the powder. By adjusting the position of the ring electrodes and the gun voltage, $\mathrm{Q} / \mathrm{M}$ could be controlled from -0.15 to $-2.15 \mu \mathrm{C} / \mathrm{g}$, which shows a much wider range of $\mathrm{Q} / \mathrm{M}$ control compared to that which could be achieved with a corona gun without a ring electrode. However, 
the application of a ring electrode reduced the electric field for powder deposition, resulting in a low first pass transfer efficiency (FPTE). The reduction of field intensity between the gun and the substrate and a strong radial field introduced by the ring, caused an expansion of the conical powder spray pattern and appearance of the cured powder films was found to be influenced by the voltage applied. An improved appearance of the cured powder film was obtained by using the ring with a smooth outer surface biased at $-20 \mathrm{kV}$, and with the corona voltage at $-100 \mathrm{kV}$. The distance between the corona electrode tip and the flat-grounded panel was $30 \mathrm{~cm}$.

\subsubsection{Research Needs in Electrostatic Processes in Powder Coating}

\section{A. Thin film powder coating}

For powder coating with film thickness smaller than $25 \mu \mathrm{m}$, using fine powders in the size range of 5-20 $\mu \mathrm{m}$ in diameter has many fundamental problems. Unless these problems are well resolved, applications of powder coating may be limited to thicker films. The research needs in the thin film powder coating areas are:

1. Dispersion of fine powders: fine powders are not easily fluidized or dispersed. The possibility of using an ordered mixture of coarse and fine powders in a fluidized bed should be investigated. The fluidized bed is designed for the fluidization of the ordered mixture of fine and coarse powder, followed by a flow transition section where only fine powder can elutriate, so only the finest particles are discharged, and the coarse particles return to the fluidizing zones. A charger is needed for unipolar charging and deposition. An alternate method would be to use a pneumatic dispersion of the fine powders with high shear forces for continuous and consistent mass flow rates.

2. Consolidation of fine powder: Fine polymer powders, even in small quantities, form agglomerates during storage, making it extremely difficult to get the primary size fraction 
after dispersion. Research is needed to study different surface treatment processes, such as plasma treatment, plasma polymerization, microencapsulation (of the powder with ultrafine powder in the sub-micron range), to minimize inter-particle attraction forces such that even when the agglomerates are formed, they can be easily separated by using a jet mill followed by an inline cyclone separator before feeding the particles to the powder coating gun.

3. UV curing of powder layer: Research work is needed to apply a thin layer of powder, followed by UV curing, to produce thin film that can be applied both on metals and nonmetals, with applications ranging from aircraft to natural or synthetic wood products. Since solvent-based application of acrylate, followed by UV curing, has been successfully applied to develop scratch-free, thin film coating, it should be possible to implement the same process with powder coating. Application of UV and electron-beam curing at room temperature with acrylate with appropriate inorganic nanoparticle additives, such as silicone dioxide, can be used for providing powder coating with superior resistance to chemical corrosion, scratches, and UV radiation, and with improved stability with respect to temperature fluctuations and ambient relative humidity. Development of hybrid powders containing polymers such as acrylates, epoxy, polyurethane, with silanes, nanoparticles and other additives, for controlling both gloss and chemical resistance needs to be investigated. The objective should be a pinhole-free thin film coating, using a commercially viable process.

4. Plasma treatment process: A post-treatment that can be applied powder-coated film to make the coated film nearly non-wettable for water, yet highly resistant to oil, is needed. 
B. Development of plasma-treated tribo-powder: The goal is to manufacture powders that will have better performance in tribocharging processes. Such powders can be used with an appropriate tribocharging gun incorporating a self-cleaning system, providing continuous contact charging between the powder and the charging material. The result should be consistent tribocharging of the powder. Development of a manufacturing process using plasma treatment should be researched in order to make powders with clean surfaces and low surface resistivities. Powders with higher surface conductance can be used for minimizing the effects of back corona on corona charging applications. Conducting powders can be applied to non-metallic surfaces such as plastics, and work with in-site UV curing. The objective would be to rapidly drain the associated charge from the powder during the deposition and UV curing processes.

C. Corona chargers: Charging guns should be developed where the charge-to-mass ratio $(\mathrm{Q} / \mathrm{M})$ of the powder can be controlled with a feedback control system so that the sprayed powder contains the right amount of charge for high transfer efficiency. Such chargers should be designed to trap excess ions. Ion-free charged powder with a high DC electric field applied by using flat parallel plates is needed for high transfer efficiency and a minimum back corona.

D. Minimalization of Faraday Cage effect: [Biris 2002, De 2003] For both corona charging and tribocharging processes, the electrostatic field produced either by the applied voltage, as in the case of the corona, or by the space charge, as in the case of the tribocharged powder, prevents the penetration of the charged particles in the recessed areas of the target. One possible method for a high penetration of the charged powder in the deep recessed area, is to use a symmetrical, bipolarly charged powder cloud with a net zero charge. There is no 
overall electric field. Each powder particle, however, can deposit on the metal surface by the image forces involved. Such a system will be a necessarily slow coating process, but a thin film can be deposited over the entire target area, irrespective of the target geometry, and the thin film should provide the desired chemical resistance against corrosion. Development of a process for coating food products with an ultrathin layer of only a few micometers in thickness should be developed for increasing shelf life of food and vegetables with a protective coating that would be edible.

E. Chromate-free conversion process: A powder coating process where the metal surface is cleaned using dry plasma treatment of the surface and pretreatment of the metal surface (aluminum alloy surface) with nanoparticles of metals and metal oxides as non-chromate conversion should be developed. Application of cerium oxide nanoparticles on an aluminum alloy, followed by thin polymer film with UV curing could provide efficient coating for aircraft, automotive, and military equipment that are often exposed in extreme temperatures, thermal cycling, mechanical vibration, and corrosive environments. The objective is to develop dry coating processes which are environmentally friendly, yet still provide corrosion resistance.

F. Color generation: Batch manufacturing processes for producing small quantities of different colored powders should be developed so that it will be possible to coat a substrate with almost any color, using the standard colors such as magenta, cyan, yellow, and black powder with an automated color matching process. The process will be similar to color copiers and laser printers. 


\subsection{Corona Reactors for Plasma Processing}

Over the last twenty years, plasma processing has been used in many industrial processes [Roth 2001]. The plasma power density can range from $\mu$ Watts to $10 \mathrm{kWatts}$ per $\mathrm{cm}^{3}$; producing active species in plasma reactors operating at a wide range of temperature: from low temperature plasma for chemical reactions to high temperature material processing applications such as making metal alloys and plasma spraying. The low power density plasma, often termed as nonthermal plasma is used including in (1) reduction of $\mathrm{NO}_{\mathrm{x}}$, (2) converting natural gas to liquid, (3) for surface modifications for coatings with better adhesion, and (4) for sterilizing biomedical implants. While plasma processing shows clearly the efficiency of energy use in many chemical reactions, there are still a number of formidable problems:

(1). The fundamental surface chemistry involved in the non-thermal corona reactors or barrier discharge processes is not clearly understood.

(2). A non-thermal barrier discharge plasma is readily applicable at a low pressure often less than $100 \mathrm{hPa}$ but many industrial applications require atmospheric operation.

(3). While corona discharge reactor operating either ac or dc high voltage can be applied at atmospheric pressure, it requires either point electrodes against a flat plate or fine wires as HV electrodes. In both systems, the active volume is small surrounding only the high voltage electrodes, and therefore the discharge process cannot be easily applied in industrial high volume, high capacity processes.

(4). In the plasma enhanced catalytic reactions, nanoparticles of different metals and metal oxides are often added to catalysts like $\mathrm{Al}_{2} \mathrm{O}_{3}, \mathrm{Cr}_{2} \mathrm{O}_{3}, \mathrm{Fe}_{2} \mathrm{O}_{3}$, and $\mathrm{V}_{2} \mathrm{O}_{5}$ for enhancing the catalytic reactions with plasma energization. Coupling the surface catalysis with plasma generated in corona reactors at atmospheric pressure is often difficult. 
To solve some of the problems, a new corona reactor was developed by Kanazawa (1997) along with their colleagues for removal of $\mathrm{NO}_{\mathrm{X}}$ from flue gas using methane. The design of the reactor is shown in Figure 18.

The corona discharge was established by using a series of point-to-plane electrodes where the point electrodes were made of small jets attached to a tube, so that the reductant gas $\left(\mathrm{CH}_{4}\right.$ and Ar) could flow through the nozzle passing through the corona discharge zone. The flue gas to be reduced was passed through the reactor. In this case, most of the reactions occurred in the gas phase and show the efficiency of $\mathrm{NO}_{\mathrm{X}}$ removal up to $40 \%$. The arrangement is shown in Figure 18 (a). Another type of corona reactor uses an array of corona wires for treating thin film or fabric, in a wire-to-plane corona discharge geometry as shown in Figure 18 (b). Here the corona ions carry the current to the surrounding walls (plane electrode) and are available for surface treatment. The UV radiation produced by corona glow can also change the surface energy of some of the materials and affect the ability of some surfaces to hold a static charge. This type of corona reactor has been used to treat non-woven webs and polymeric and plastic films to induce higher surface energy and wettability for applications involving printability.

An important advantage of corona reactors is that they can operate at one atmospheric pressure and at low input power. However, the major disadvantage of current technology in corona reactors are: (a) low energy ions cannot react chemically to produce a range of energetic active species that are often required, (b) both the rate of formation and the surface area available are limited, (c) corona reactors often cause interference by generating rf waves, (d) generation of UV radiation, (e) ozone production, and (f) the requirement of high voltage. A more efficient corona reactor is needed to take advantage of plasma energization of many reactions needed in many 
industrial processes, and considerable research is needed for their application in energy and environmental engineering processes.

\subsubsection{Effect of Plasma Treatment ON Electrostatic Properties of Polymer POWDERS}

In this study, an atmospheric pressure helium plasma treatment was employed to (1) reduce surface charge density caused by tribocharging and (2) decrease surface resistivity of polymer powders. Surface modification of a test polymer powder was carried out using inert plasma in a fluidized bed reactor (Figure 19) operating at atmospheric pressure. A capacitatively coupled plasma generator was used to operate at a frequency of $700 \mathrm{~Hz}$. The voltage across the electrodes was $12 \mathrm{kV}_{\mathrm{rms}}$. The electrostatic charging characteristics of the test polymer powder were studied before and after plasma treatment. Tribocharging data after plasma treatment showed a decrease in the net acquired charge-to-mass ratio $(\mathrm{Q} / \mathrm{M})$ as compared to that of unmodified powders (Figure 20) [Sharma 2004]. It was also found that plasma treatment significantly enhanced the charge decay rate of acrylic polymer powder [Sharma 2003]. The charge decay time constant for plasma treated powder was 458 minutes at $18 \% \mathrm{RH}$ compared to 996 minutes for untreated powder.

\subsubsection{Research Needs in Plasma/Corona Reactors}

A. Both fundamental studies and experimental research are needed to develop plasma processes, either using a glow-discharge or corona reactor that can be applied for different industrial and medical applications. Plasma discharge can be used both for cleaning and polymerization. Plasma treatment is widely used in increasing adhesion for bonding and coating. Surface modification and cross-linking can be performed to produce both water and oil resistant film with high strength and flexibility, and is needed (1) in aircraft and missiles, (2) for treating fabrics for excellent resistance to chemicals, fire, and biological particles, and (3) for 
production of thin film coatings that are pinhole-free, that can be applied to almost any surface. Plasma treatment application to control of tribocharging properties, and to increase surface conductivities, should further be explored. Extensive research is underway for applying plasma for converting natural gas to liquid fuel and for reducing nitrogen oxides, an acid rain precursor pollutant in flue gases, to pure nitrogen.

\subsection{Emerging Areas in Electrostatic Applications}

The 2002 Nobel Prize in chemistry awarded to Prof. John Fenn is a landmark in the area of electrostatics, where the identification of different proteins is made possible by using an electrospray nozzle of a few micrometers in diameter capable of producing a mist of charged bio-particles. Proteomics is becoming a major field in the area of biological science. Understanding of the electrostatic charging of biological particles at different $\mathrm{pH}$ level, and possible minimization of protein deposition on the surface by controlling the electrostatic charge on the implant for a better blood compatibility by minimizing the deposition of fibrinogen on cardiovascular implants is required.

Some of the emerging areas of the application of electrostatics are:

(1) electrospray technology and its application in Proteomics, where the individual proteins are identified applying ionization mass spectroscopy following an electrospray process,

(2) bio-electrostatics, where a better understanding of the electrostatic charge properties of biological particles, and how the charges influence their motion and deposition on a surface are needed,

(3) layer-by-layer coating in which extremely fine films, of the order of few micrometers, are deposited to provide protection against bacterial invasion, and are used for protecting agricultural products. 
(4) the electrostatic properties of nanoparticles and their deposition on different substrates under dry conditions,

(5) micro-electrochemical systems, microfludics, electrodynamic manipulation of biological

particles and electrostatic micro- and nano-motors, and their application to industry and medicine.

\subsection{CONCLUSION}

Electrostatic phenomena have been known to man for over thousand years. Only during the past century have a number of major applications of electrostatics evolved, including electrostatic precipitators, electrophotography (copying machines and laser printers), powder coating, corona reactors for plasma treatment, electrospray ionization mass spectroscopy and its application to Proteomics. Electrostatic manipulation of bio-particles, electrostatic micro-motors, application of plasma to microelectronics, and micro-mechanical systems are examples of growing fields in electrostatic engineering.

\subsection{REFERENCES}

Atten, A and Oliveri, S. (1992), Charging of drops formed by circular jet breakup, Journal of Electrostatics, 29, pp. 73-91.

Bailey A., et al. (1998), Drug Delivery by Inhalation of Charged Particles, Journal of Electrostatics, Vol. 44, pp. 3-10.

Balachandran W., et al. (1997), Control of drug aerosol in human airways using electrostatic forces, Journal of Electrostatics, Vol. 40\&41, pp. 579-584. 
Baron P.A, et al. (2001), Direct-Reading Techniques Using Optical Particle Detection, Aerosol Measurement - Principles Techniques and Applications, New York, John Wiley \& Sons, 381409.

Biris A.S., et al. (2001), Gloss and Texture Control of Powder Coated Films: Electrostatics and Particle Size Effect, Particulate Science and Technology an International Journal, Vol. 19 (3), pp. $199-217$.

Biris, A.S., et al. (2002), Parametric study of the Faraday cage effect of charged particles and its implications in the powder coating process, Industry Applications Conference, 2002. 37th IAS Annual Meeting. Conference Record of the ,Vol 2, 13-18, pp. $995-1000$.

Biris A.S., et al. (2003a), The Effect of Ring Electrodes Attachment to a Corona Gun on a control of Free Ion concentration and Back Corona for Powder Paint Appearance, IEEE Transactions on Industry Applications, Vol 39, No. 6.

Biris A.S., et al. (2003b), Surface Analysis and Electrochemical Study of Gold Nanoparticles Treated Metallic Surfaces, First Joint IEEE-ESA Annual Meeting, Little Rock.

Chang J., (1995) in Handbook for Electrostatic Processes, A. J. Kelly and J. M. Crawley (eds.), Marcel Dekker, New York, pp. 773-747.

Chang J.S., et al. (1991), Corona Discharge Process, IEEE Transactions on Plasma Science, Vol. 19, No. 6, 1152-1166.

Cho, A. H. Y. (1961), Contact charging of micron-size particles in intense electric fields, Journal of Applied Physics 35, pp. 2561-2565. 
Cross J.A., (1987), Electrostatic Principles, Problems and Applications, Adam Hilger, Bristol, U. K.

Cross J.A., et al. (1998), An analysis of the current in a point to plan corona discharge and the effect of a porous insulating layer on the plane, Journal Applied Photonic Engineering, Vol. 7, pp. 121-125.

De, S. et al. (2002a), Surface defects and corrosion in electrostatically deposited powder films, Industry Applications Conference, 2002. 37th IAS Annual Meeting, Vol. 4, 2460 -2465, 13-18.

De S., et al. (2002b), Electrostatic Microencapsulation Technique for Producing Composite Particles, Particulate Science and Technology an International Journal, Vol. 20, pp. 1-17.

De S., et al. (2003), A statistical Model for Analyzing the Faraday Cage Effect in Powder Coating Applications, Proceedings of the First Joint Meeting IEEE-IAS and Electrostatics Society of America (ESA), pp. 602-612, Little Rock, Arkansas.

Grable N.C., et al. (2001), Application of boxer charger for charging polymer powder without free ion current, Ind. Appl. Conf., 2001. Thirty-Sixth IAS Annual Meeting. Conference Record of the 2001 IEEE, Vol. 4, 30, pp. $2268-2271$.

Gidaspow D., et al., (1987), Separation of pyrites from Illinois coals using electofludized beds and electrostatic sieve conveyors, in Processing and Utilization of High Sulfur Coals II, Y. P. Chugh and R. D. Caudle (eds.), Elseiver Science, New York. 
Hendricks, C.D. and Schnieder, J.M. (1963), "Stability of a conduction droplet under influence of surface tension and electrostatic forces", American Journal of Physics, 31, pp. 450-453.

Hughes J.F., (1985), Electrostatic Powder Coating, Research Studies Press and Wiley, New York.

Landis G. A., (1996), Dust Obscuration of Mars Photovoltaic Arrays, Acta Astronautica, 38 (11), pp. $885-891$.

Kanazawa S., et al. (1997), Removal of $\mathrm{NO}_{\mathrm{X}}$ from flue gas by corona discharge activated methane radical showers, Journal of Electrostatics, Vol. 40 \& 41, pp. 651-656.

Magnusson M.H., et al. (1999), Gold nanoparticles: Production, reshaping, and thermal charging, Journal of Nanoparticle Research, Vol. 1, pp. 243-251.

Masuda S., et al. (1978), Boxer Charger in Conf. IEEE/IAS Annual Proceedings, 1B, pp. 16-22.

Masuda S., et al. (1988), Movement of blood cells in liquid by non-uniform traveling field, IEEE Transactions on Industrial Applications, Vol. 24(2), 217- 222.

Mazumder, M.K., (1998), Electrostatic Processes, in: Encyclopedia of Electrical and Electronic Engineering. Vol. 7, Wiley, New York, pp. 15-39.

Moesner F. M., Higuchi T., (1997), Traveling electric field conveyor for contact less manipulation of microparts, IEEE Industry Applications Society, Annual Meeting New Orleans, Vol. 3, pp. 2004-2011. 
Mountain, J. R. and Mazumder, M.K., (2001) Triboelectric Charging of Polymer Powders in Fluidization and Transport Processes", IEEE Transactions on Industry Applications, Vol 37, No. 3, pp. 778-784.

Ralston O.C., (1961), Electrostatic Separation of Mixed Granular Solids, Elseiver, Amsterdam.

Roth J.R., (2001), Industrial Plasma Engineering, Vol 1 \& 2, Institute of Physics Publishing, Bristol, UK

Saini D., et al. (2002), Drug delivery studies on electrostatically charged dry powder inhaler aerosols using a glass bead lung mode, Industry Applications Conference, 2002. 37th IAS Annual Meeting, Vol 4, pp. 2451-2453.

Schein L.B., (1988), Electrophotography and Development Physics, Springer-Verlag, New York.

Sharma R., et al. (2003), Effect of Ambient Relative Humidity and Surface Modification on the Charge Decay Properties of Polymer Powders in Powder Coating, IEEE Transactions on Industry Applications, Vol. 39 (1), pp. 87-95.

Sharma R., et al. (2004), Modification of Electrostatic Properties of Polymer powders using Atmospheric Plasma Reactor, Polymer Surface Modification: Relevance to Adhesion, Volume 3, Ed: K.L. Mittal; c. 450 pages; VSP, AH Zeist, The Netherlands, pp. 25 - 37.

Srirama P.K., et al. (2003), Development of a portable electrostatic charge separator, Proceedings ESA-IEEE Joint Meeting on Electrostatics, pp. 241-247. 
Trigwell S., (2003a), "Correlation between Surface structure and Tribocharging of Powders," Ph.D. dissertation, Dept. App. Sci., Univ. of Arkansas at Little Rock, Little Rock, AR.

Trigwell S., et al. (2003b), Precombustion Cleaning of Coal by Triboelectric Separation of Minerals, Particulate Science and Technology, Vol. 21, No. 4, pp. 353-364.

White, H. J. (1951), Particle Charging in Electrostatic Precipitation, AIEE Transactions 70, pp. $1186-1191$.

White H.J., (1963), Industrial Electrostatic Precipitation, Pergamon, Oxford. 


\section{Figure Captions}

Figure 1. A corona charging process for producing unipolarly charged powder with reciprocating grids for collecting ions while being continuously cleaned.

Figure 2. Details of the Boxer Charger charging unit along with the Powder feed, sheath airflow, ozone trap, and Faraday pail.

Figure 3. Spinning Disk Generator of Charged Droplets.

Figure 4. Measured vs. reported work functions.

Figure $5 \mathrm{The} \mathrm{Q} / \mathrm{M}$ of the acrylic and epoxy powders as a function of the work function difference between the powders and charging material.

Figure 6. (a) A photograph of the charge separator. (b) The charge separation data for three lactose powders commonly used in the pharmaceutical industry. They were tribocharged against stainless steel for 5 minutes and blown off inside the charge separator.

Figure 7. Basic Schematic of the ESPART Analyzer

Figure 8. Size range and resolution of ESPART

Figure 9. Schematic of Charge Separator.

Figure 10. Sulfur and ash reduction for beneficiation of Pittsburgh No. 8 coal powder using a two-stage electrostatic separation process. 
Figure 11. Electrostatic microencapsulation tower using two Corona guns for charging guest and host particles with opposite polarity. A grounded wire mesh is used for applying the electric field. The AC field is used for enhancing coagulation.

Figure12. The setup used to generate gold nanoparticles consists of a gold wire in a point-toplane geometry.

Figure13. The average size of the gold and tungsten nanoparticles generated at different voltages applied to the corona electrodes when the distance to the substrate was kept constant at $1.5 \mathrm{~cm}$.

Figure 14. (a) Schematic diagram of the electrodynamic screen. (b) Cross-section showing the positioning of the electrodes within the clear cover over the solar panel.

Figure 15. A surrogate glass bead lung model for studying the site-specific deposition system to study the effect of charge on drug particles.

Fig 16. DPI sampling system interfaced to ESPART Analyzer for powder PSD and charge spectral analyses of aerosol sampled at different inhalation flow rates and at different ambient $\mathrm{RH}$ and temperatures.

Figure 17. (a) Schematic of target and gun with ring electrode configuration (b) the electrical field distribution in the inter-electrode spaces between the corona electrode and the grounded target (c) and between the corona electrode, the ring electrode, and the grounded target 
Figure 18. Corona reactors with an array of shower electrodes or wires and flat plates for plasma treatment. (a) Corona reactor for Methane Conversion, (b) Corona Reactor for treating web or fabric

Figure 19. Fluidized bed atmospheric plasma reactor.

Figure 20. Charge-to-mass ratio of control and plasma treated acrylic polymer powder. 


\section{Tables}

Table 1: XPS data. Elemental compositions presented as relative atomic $\%$

\begin{tabular}{|c|c|c|c|c|c|c|c|c|c|c|c|c|c|c|c|c|}
\hline & C & $\mathbf{O}$ & $\mathbf{N}$ & $\mathbf{N a}$ & Si & $\mathbf{C u}$ & $\mathbf{F e}$ & $\mathrm{Cr}$ & Ag & Al & Mg & $\mathbf{F}$ & $\mathbf{C a}$ & $\mathbf{Z n}$ & Cl & $\mathbf{S}$ \\
\hline Aluminum & 23 & 53 & - & - & - & - & - & - & - & 24 & 1.2 & - & - & - & 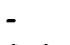 & - \\
\hline Silver & 40 & 16 & - & - & - & - & - & - & 40 & - & - & - & - & - & 2.6 & - \\
\hline$\alpha$ - alumina & 3.2 & 67 & - & - & - & - & - & - & - & 30 & - & - & - & - & - & - \\
\hline 316L steel & 53 & 35 & 0.8 & - & 0.9 & - & 8.7 & 1.7 & - & - & - & - & - & - & - & - \\
\hline Graphite & 98 & 2.3 & - & - & - & - & - & - & - & - & - & - & - & - & - & - \\
\hline Copper & 70 & 21 & - & - & 1.4 & 7.4 & - & - & - & - & - & - & - & - & - & - \\
\hline $\mathrm{SiO}_{2}$ & 9.9 & 64 & - & 0.6 & 26 & - & - & - & - & - & - & - & 0.7 & - & - & - \\
\hline Glass & 15 & 55 & - & 9.5 & 17 & $\therefore$ & - & - & - & - & 2.9 & - & 0.7 & - & - & - \\
\hline Electro. 316L & 69 & 24 & 2.1 & 1.8 & 1.3 & - & 0.8 & 0.7 & - & 1.1 & - & 0.2 & 0.3 & 0.3 & 0.3 & - \\
\hline Vitrinite & 68 & 25 & 1.1 & 0.3 & 2.9 & - & - & - & - & 2.4 & - & - & - & - & - & 0.7 \\
\hline Polystyrene & 75 & 21 & 2.4 & 1.2 & - & - & - & - & - & - & - & - & 0.3 & - & - & 0.7 \\
\hline Pyrite & 51 & 27 & - & 0.6 & - & - & 5.4 & - & - & - & - & - & - & 0.4 & 1.4 & 14 \\
\hline Acrylic & 73 & 27 & - & - & - & - & - & - & - & - & - & - & - & - & - & - \\
\hline Polycarbonate & 84 & 16 & - & 0.1 & 0.2 & - & - & - & - & - & - & - & - & 0.1 & 0.1 & - \\
\hline Nylon 66 & 79 & 13 & 7.8 & - & 0.2 & - & - & - & - & - & - & - & - & - & - & - \\
\hline PTFE & 30 & 0.2 & - & - & - & - & - & - & - & - & - & 70 & - & - & - & - \\
\hline
\end{tabular}




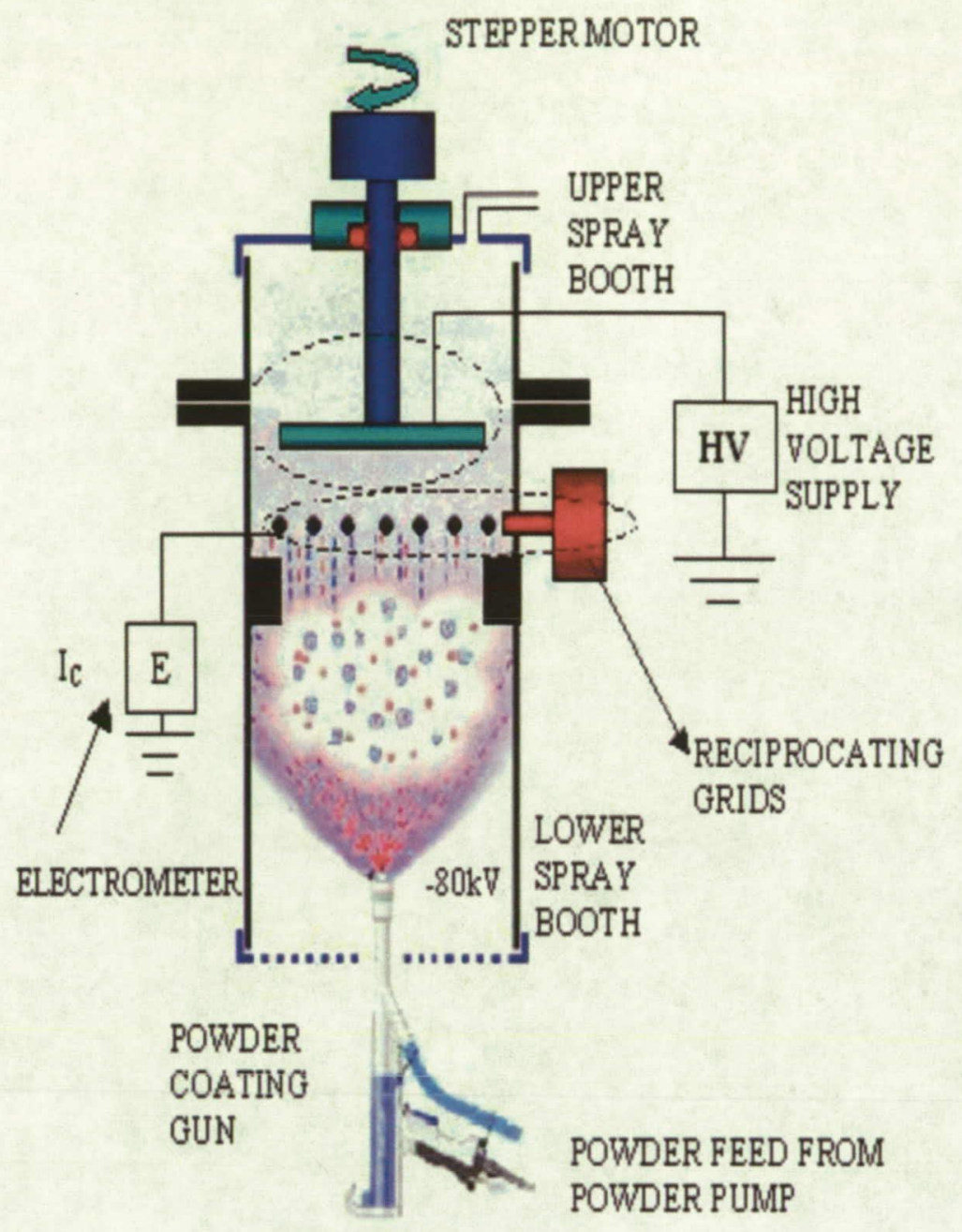

FIG. I 


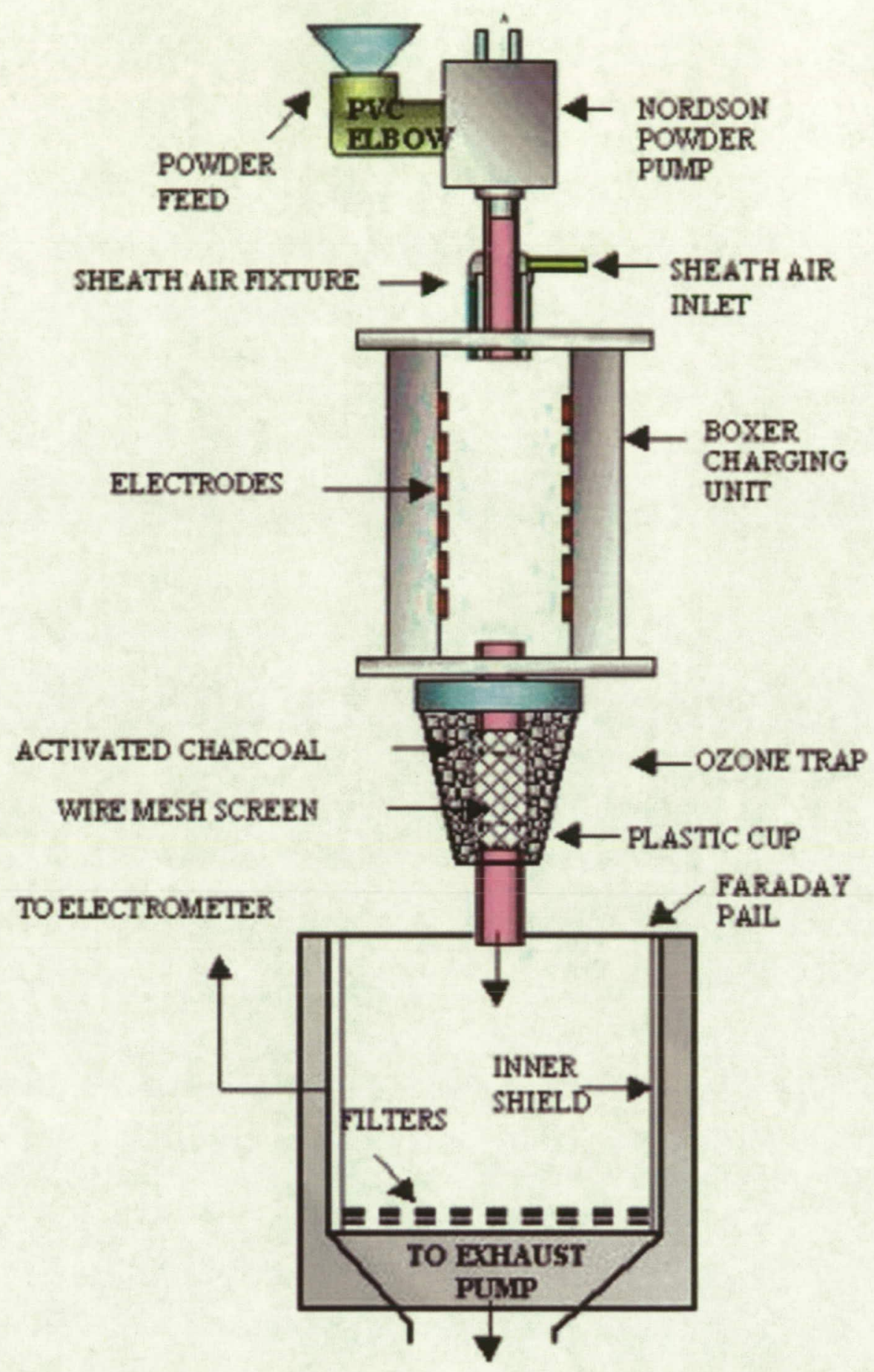

FIG. 2 


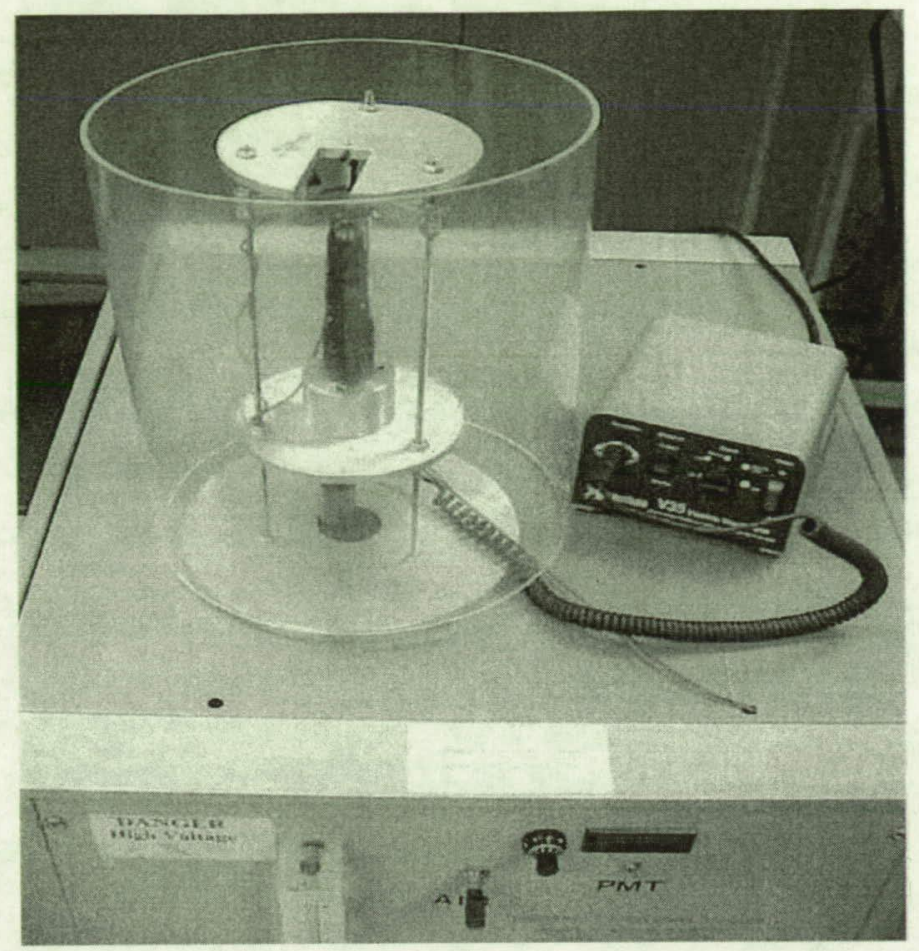

FIG. 3 


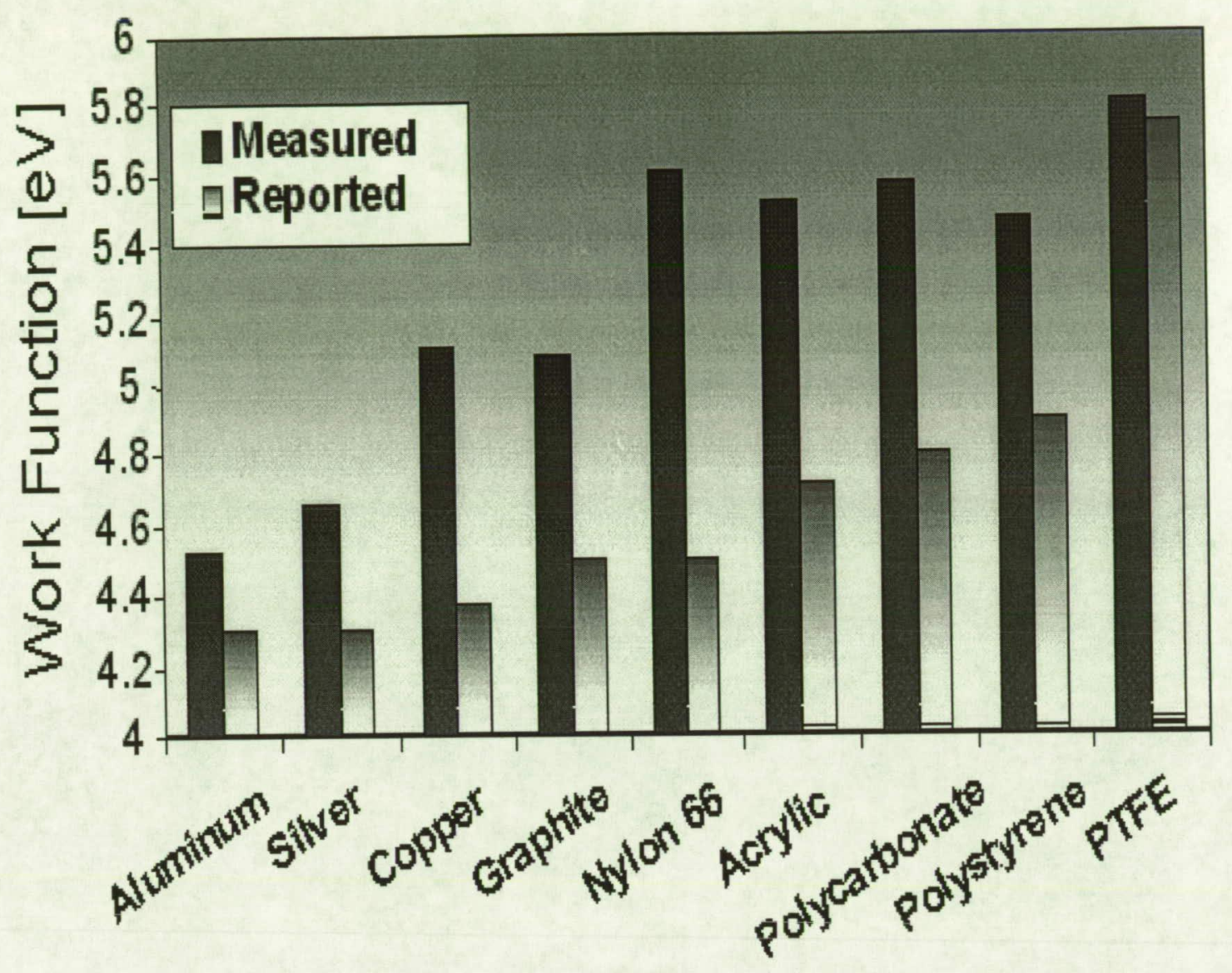

FIG. 4 


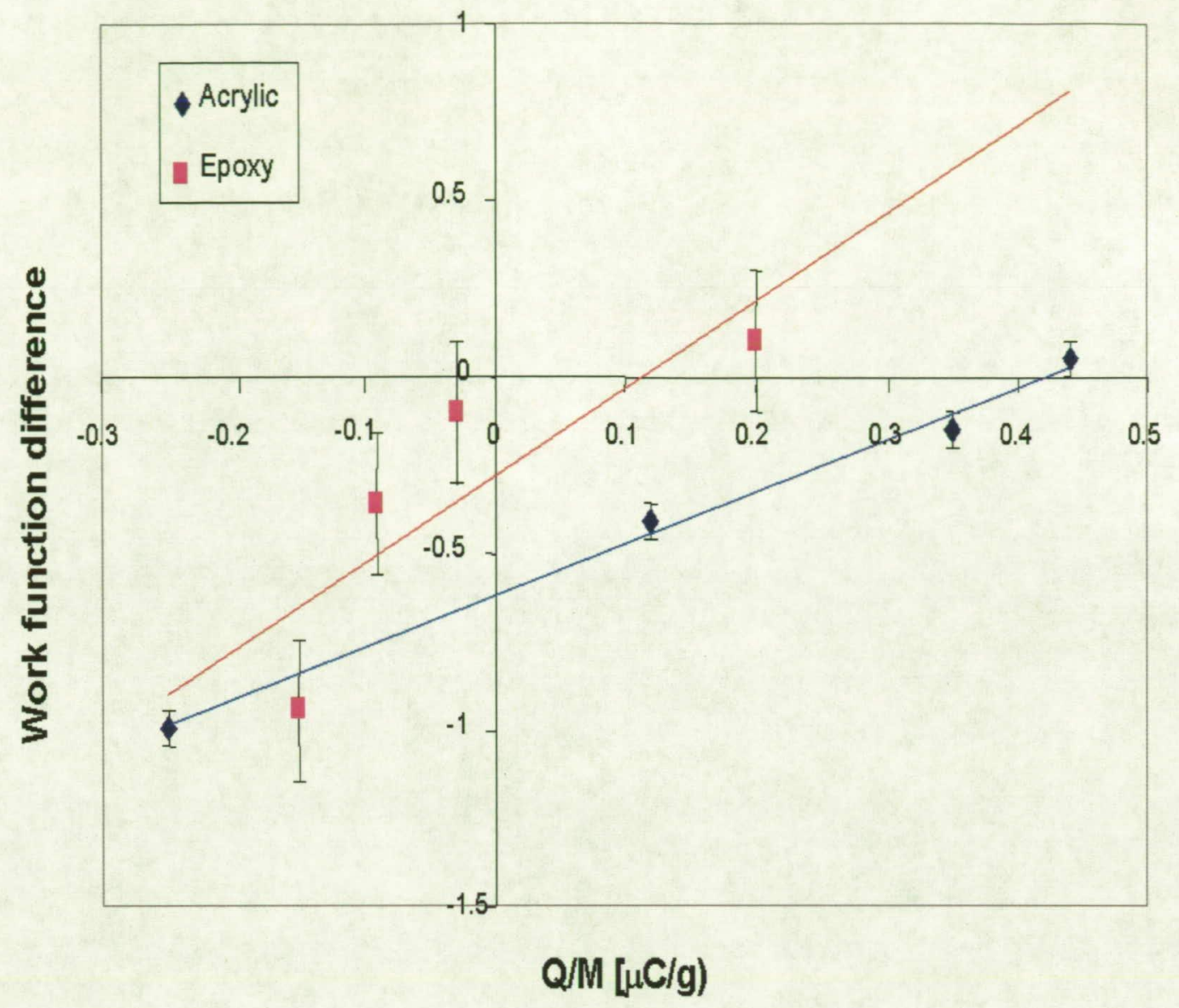

FIG. 5 


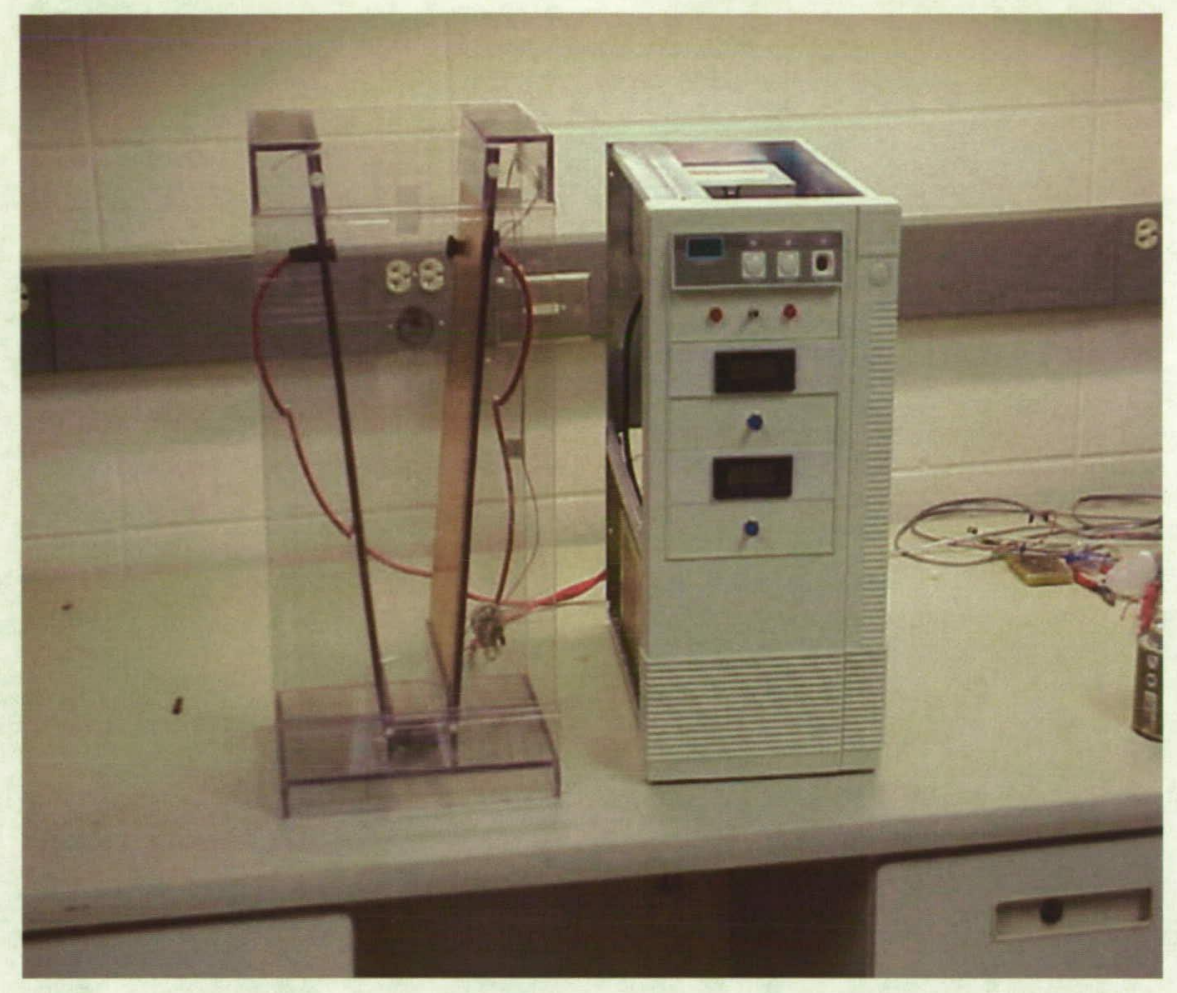

$F 16.6(a)$ 


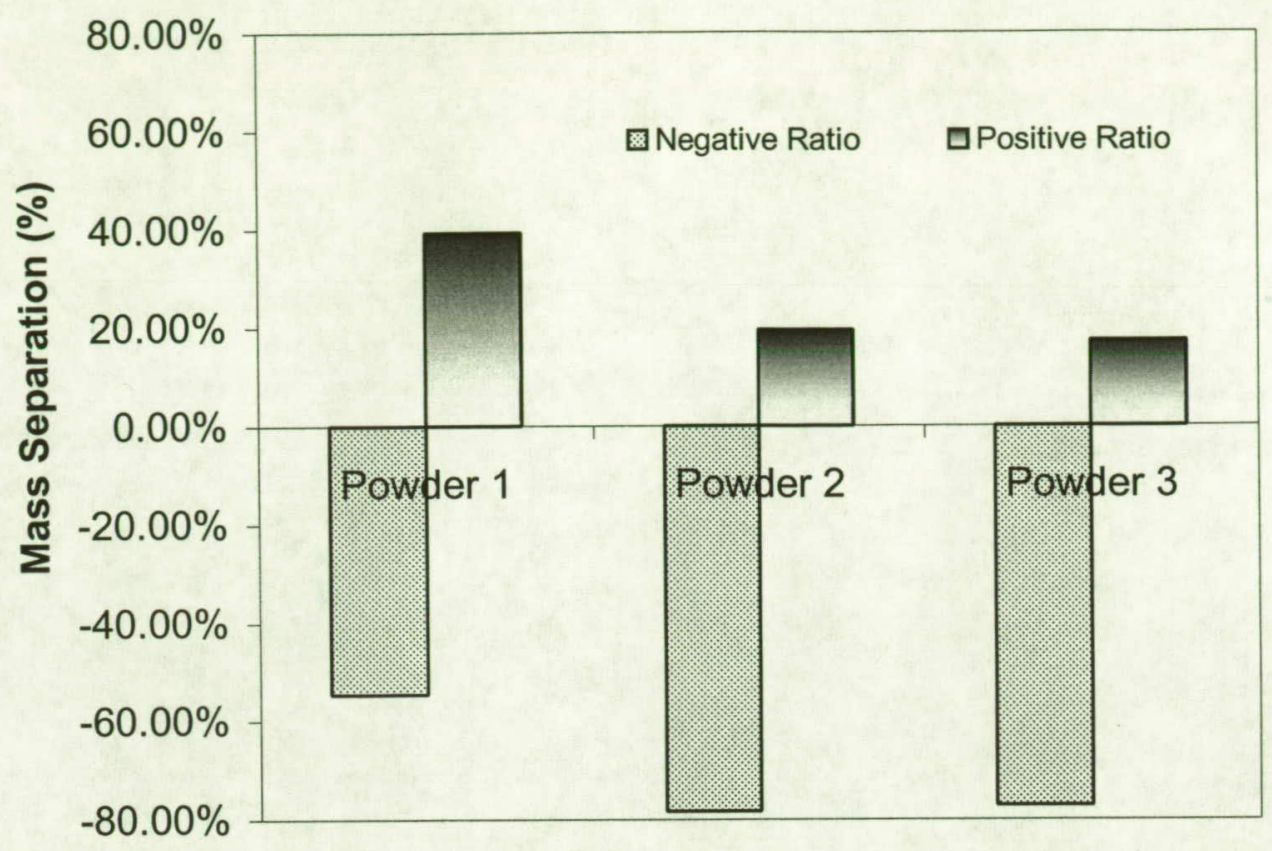

$F \mid G . f(b)$ 


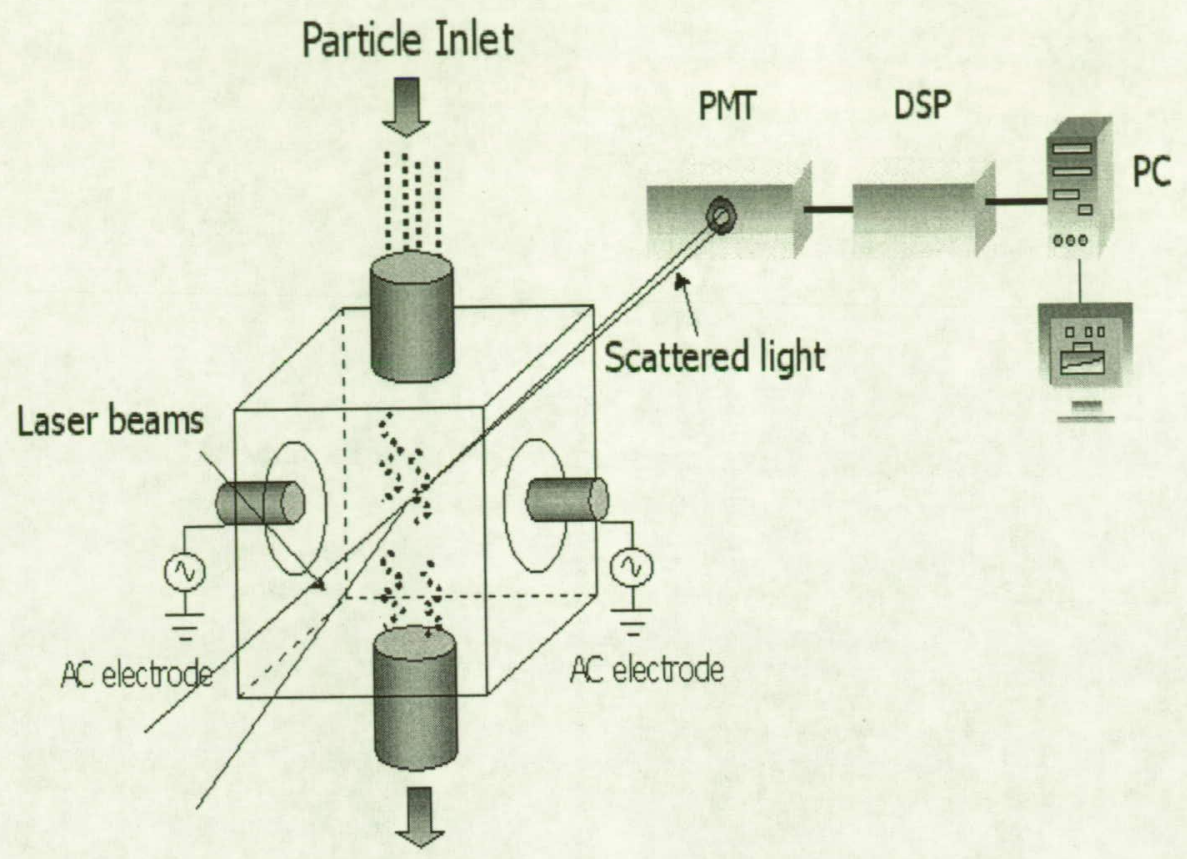

FIG. 7 


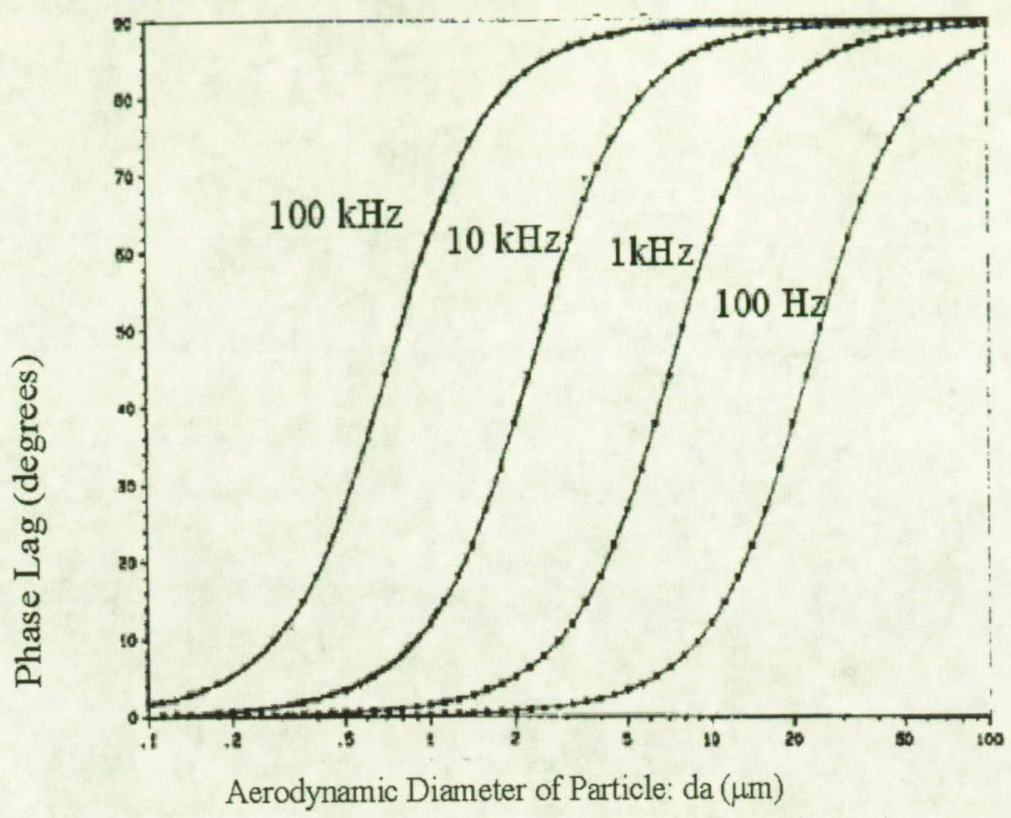

FIG. 8 


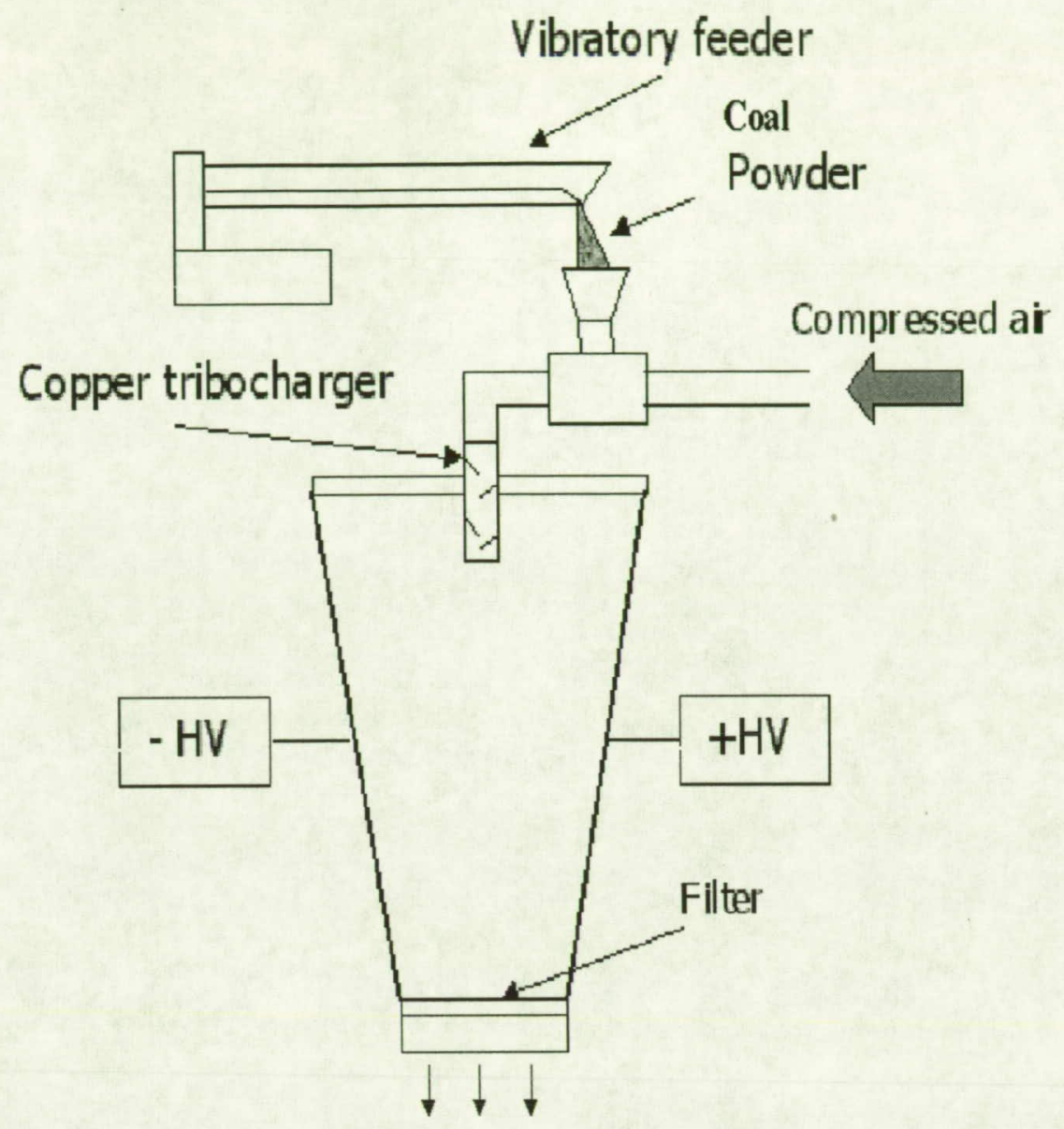

FIG. 49 


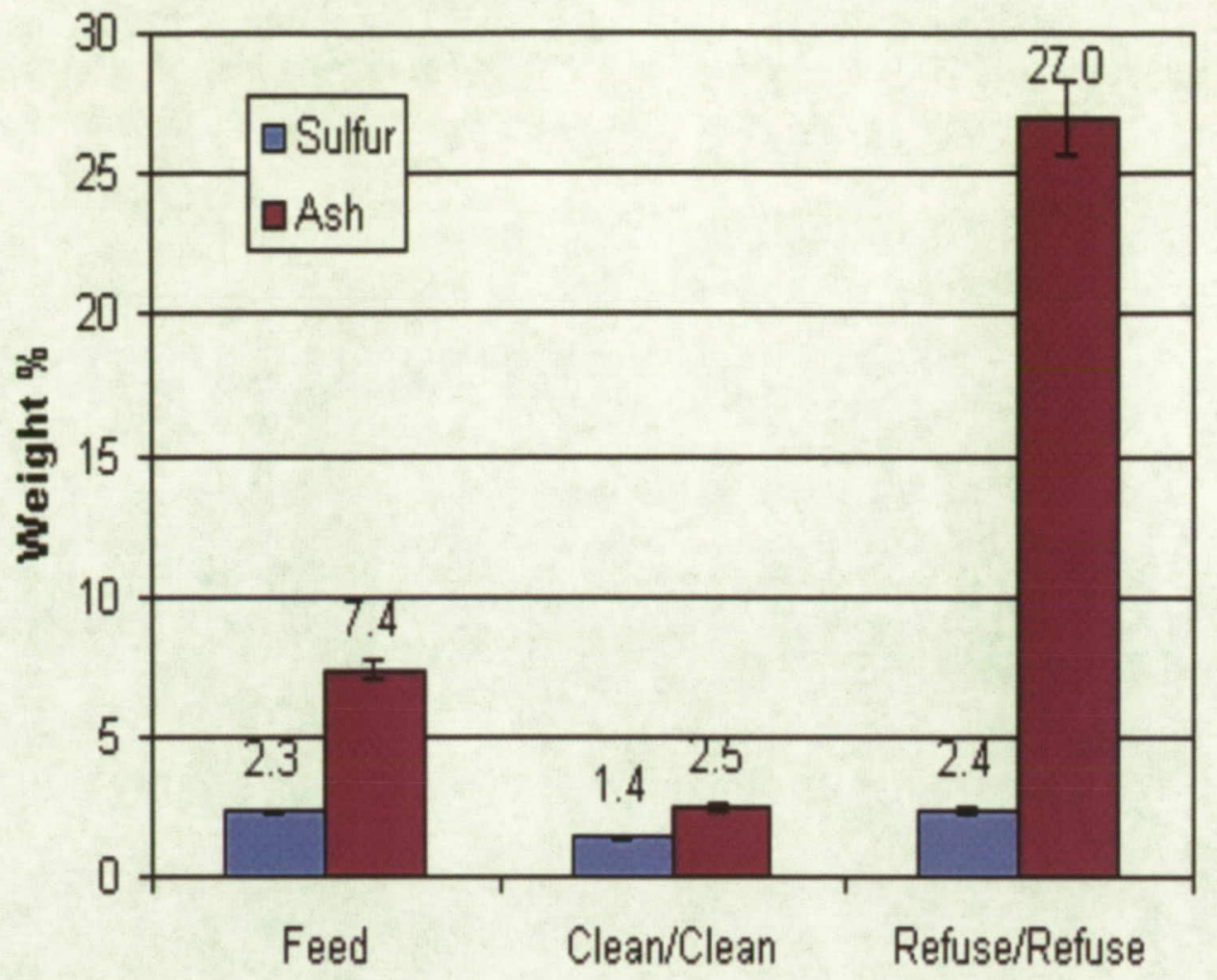

FIG. 10 


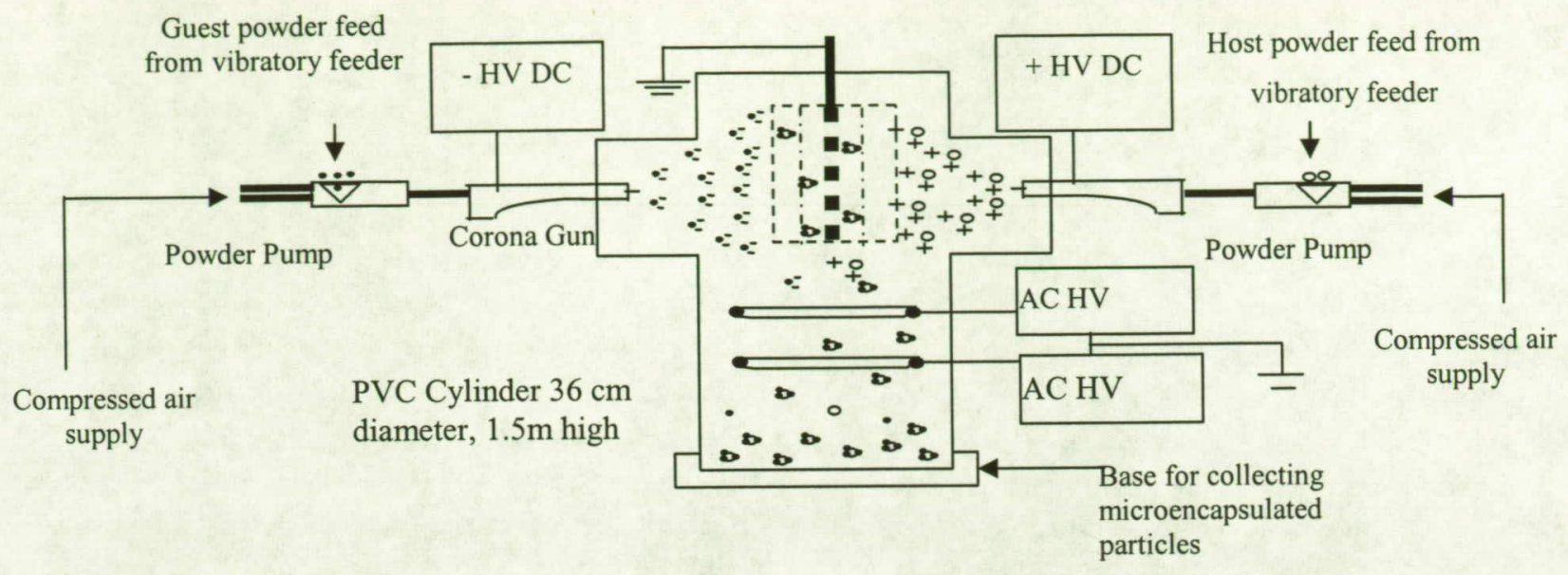

FIG. II 


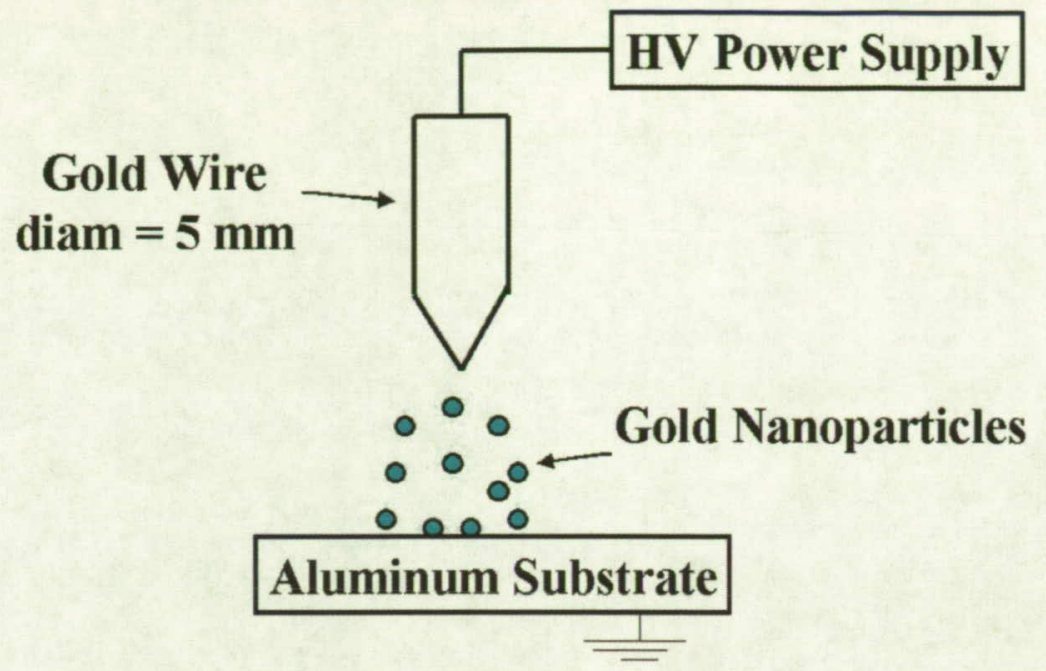

FIG. 12 


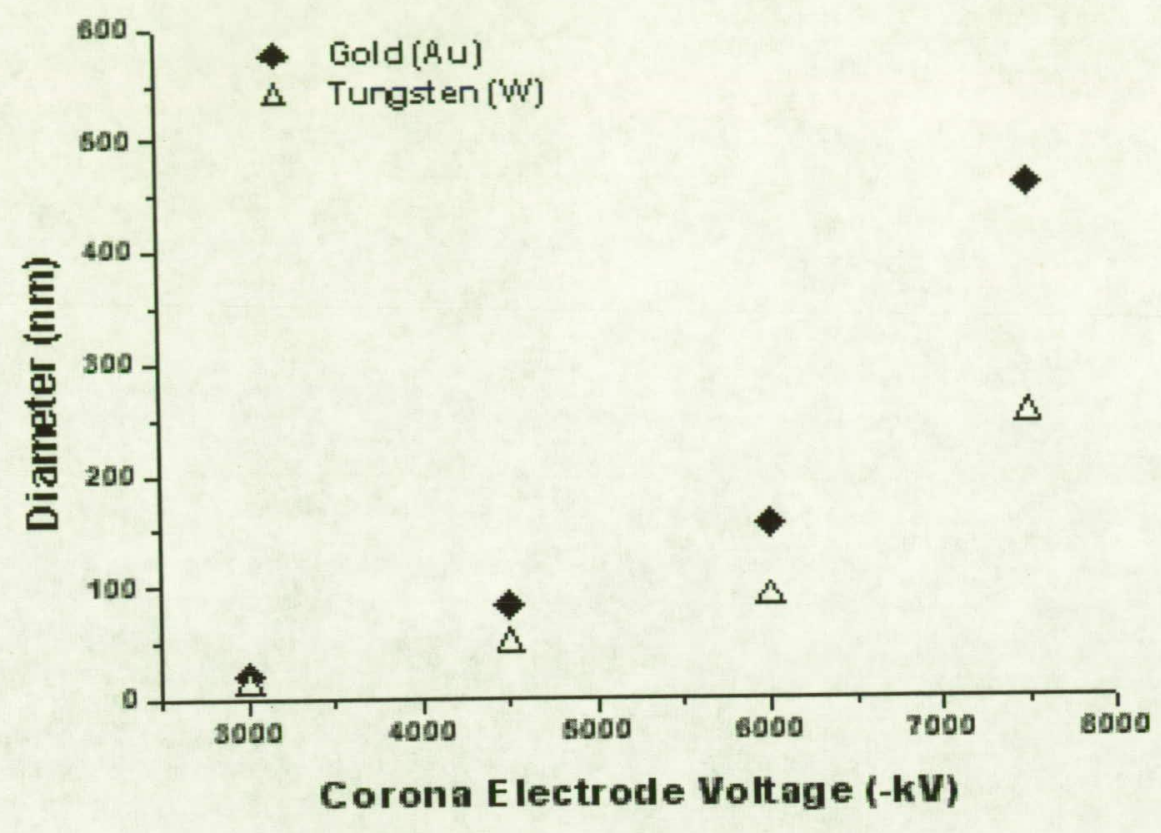

$F \mid G, 13$ 

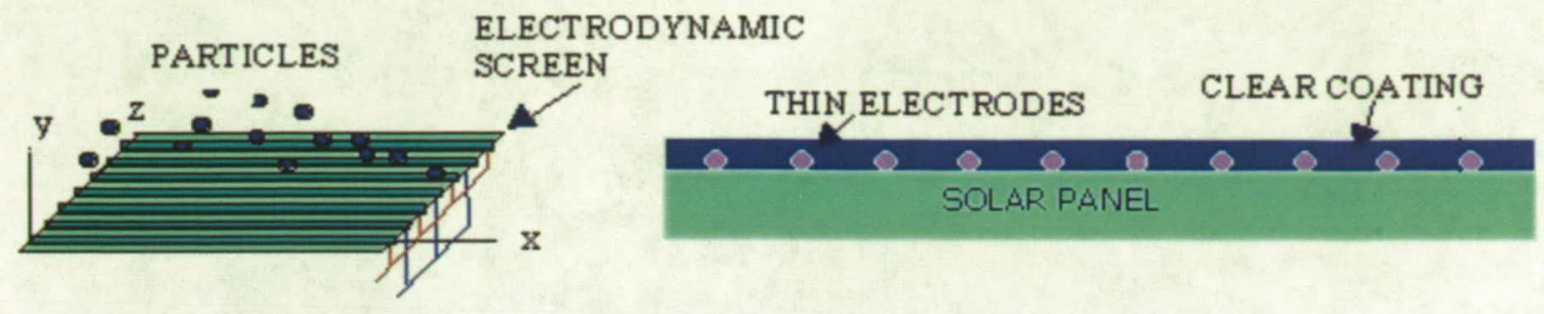

(a)

(b)

FIG. 14 


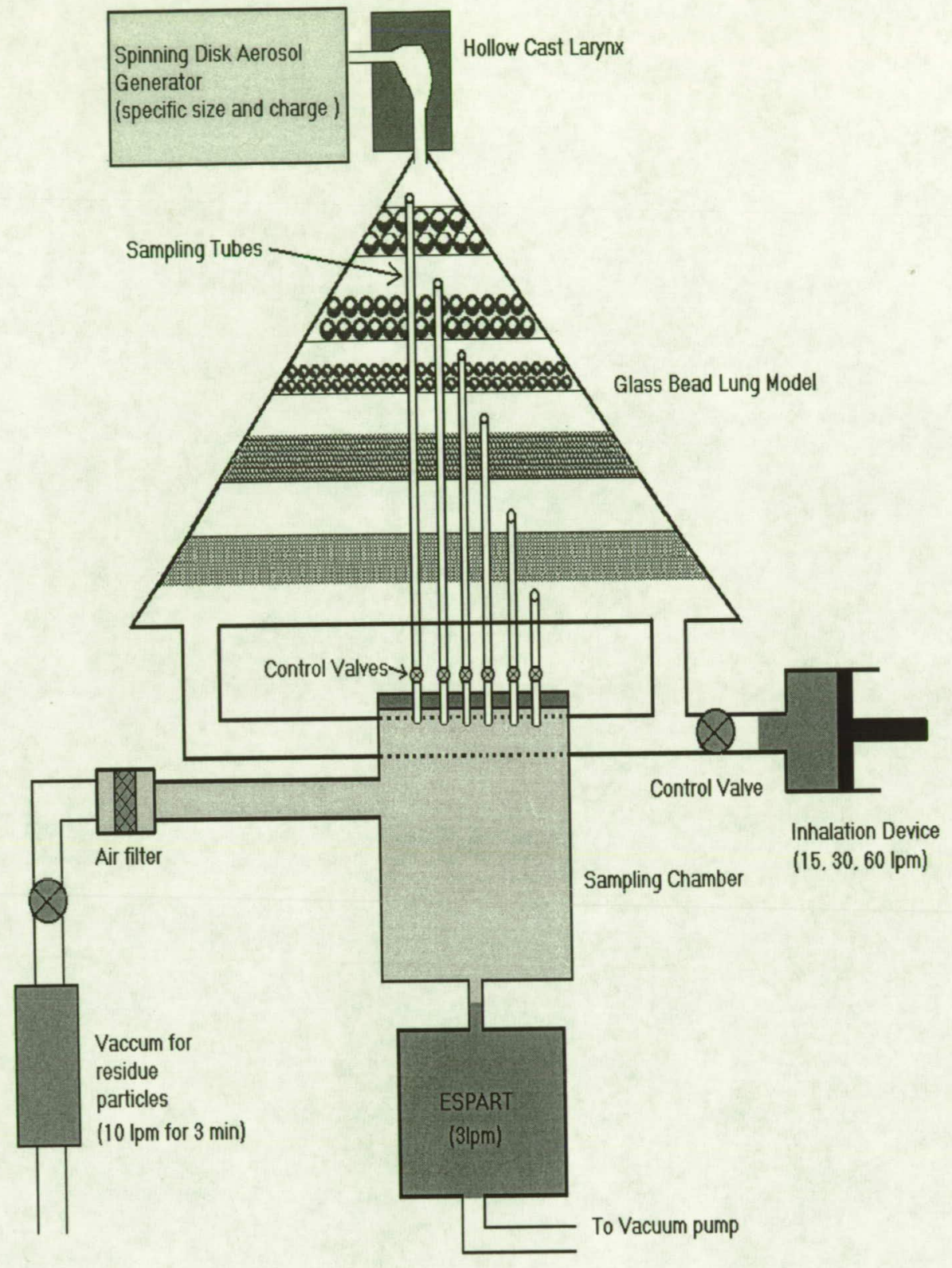

$F I G, 15$ 


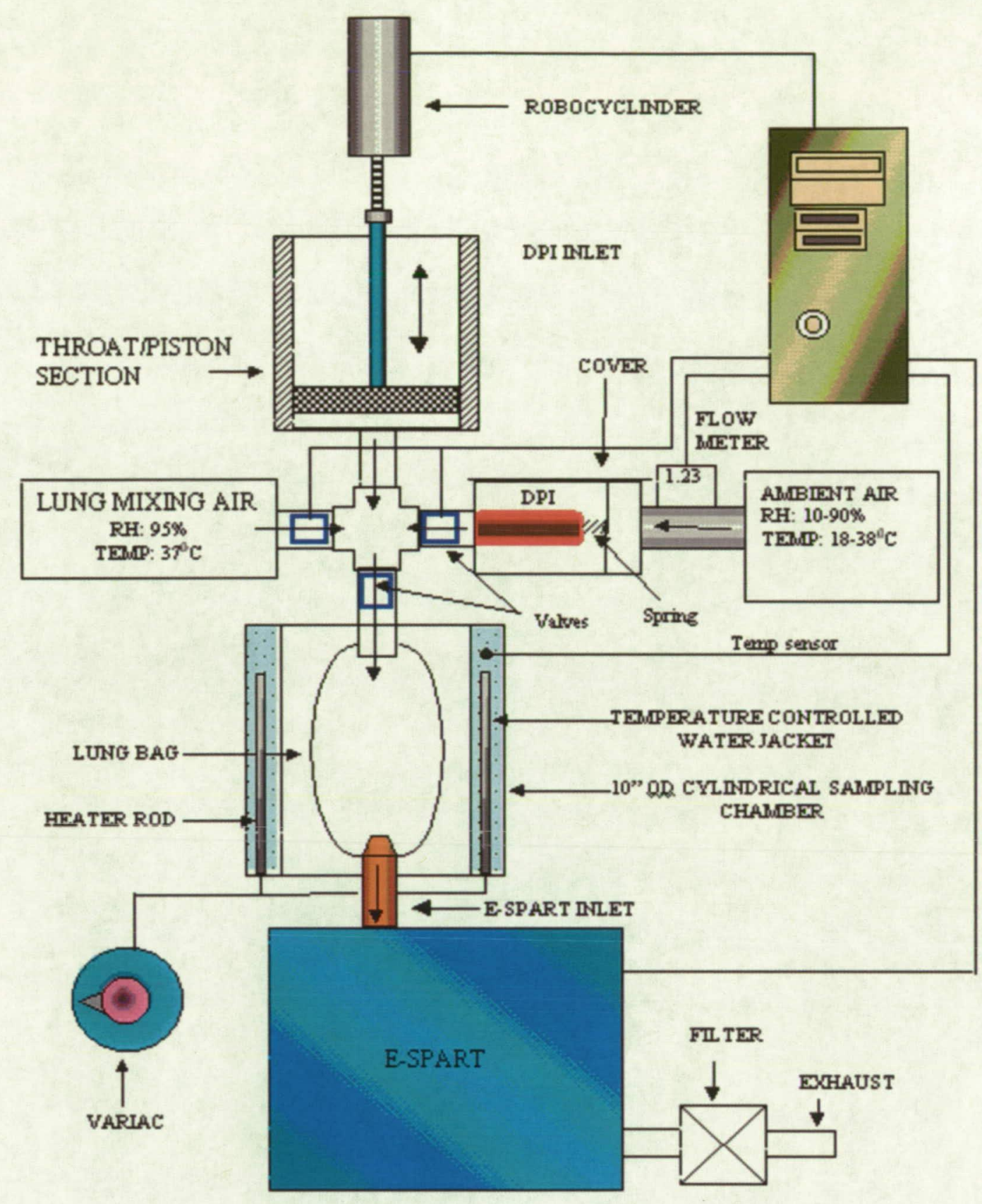

$F \mid G .16$ 


$$
=\mathrm{O} T
$$




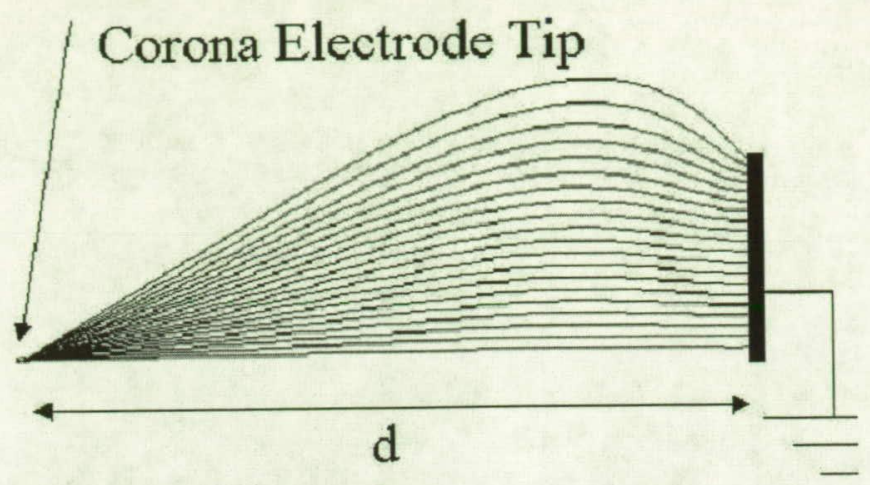

No Ring Electrode

$F / G .17(6)$ 


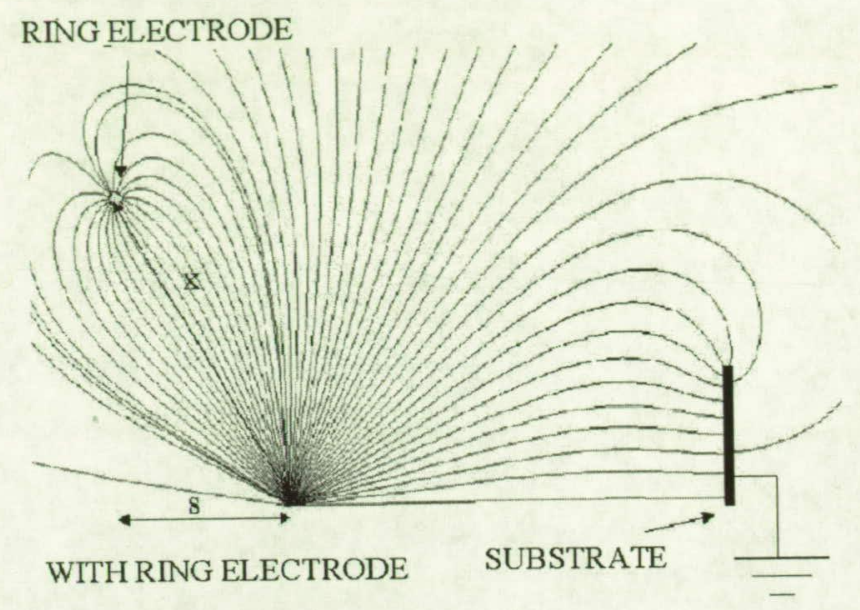

FIG. $17(c)$ 


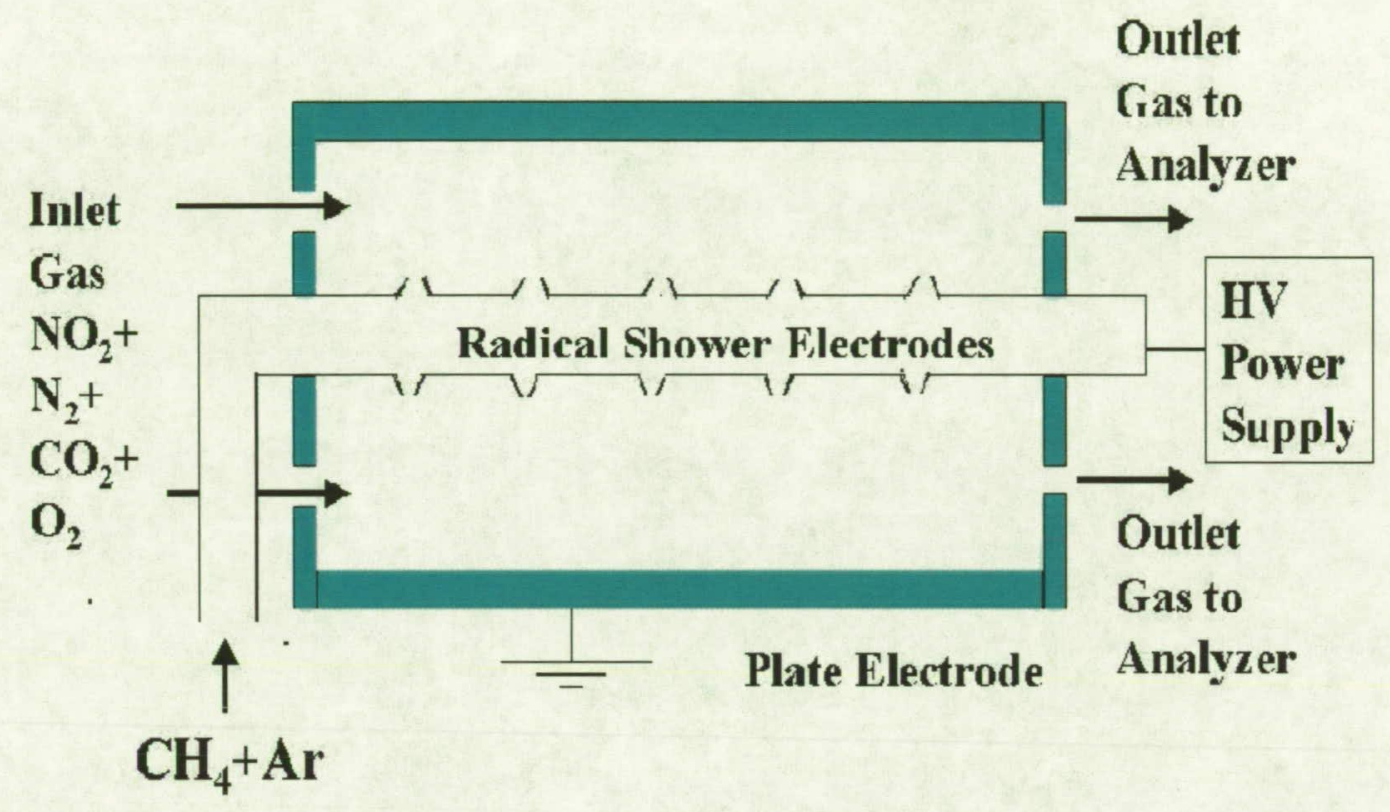

$F / G .18(a)$ 


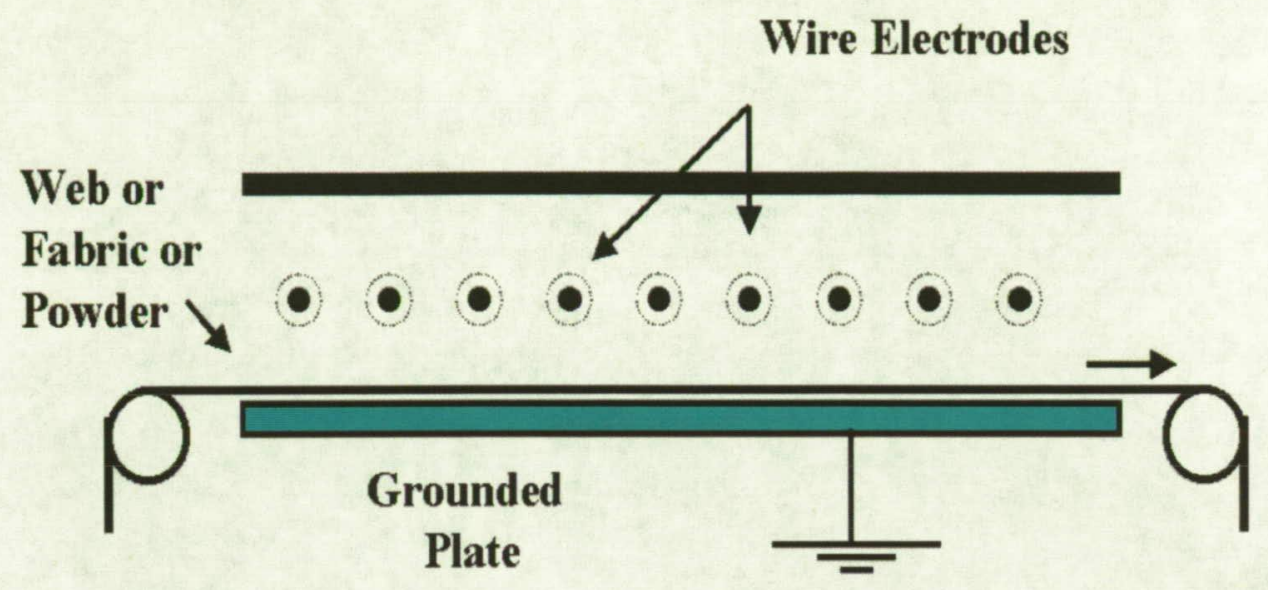

FIG. $18(6)$ 


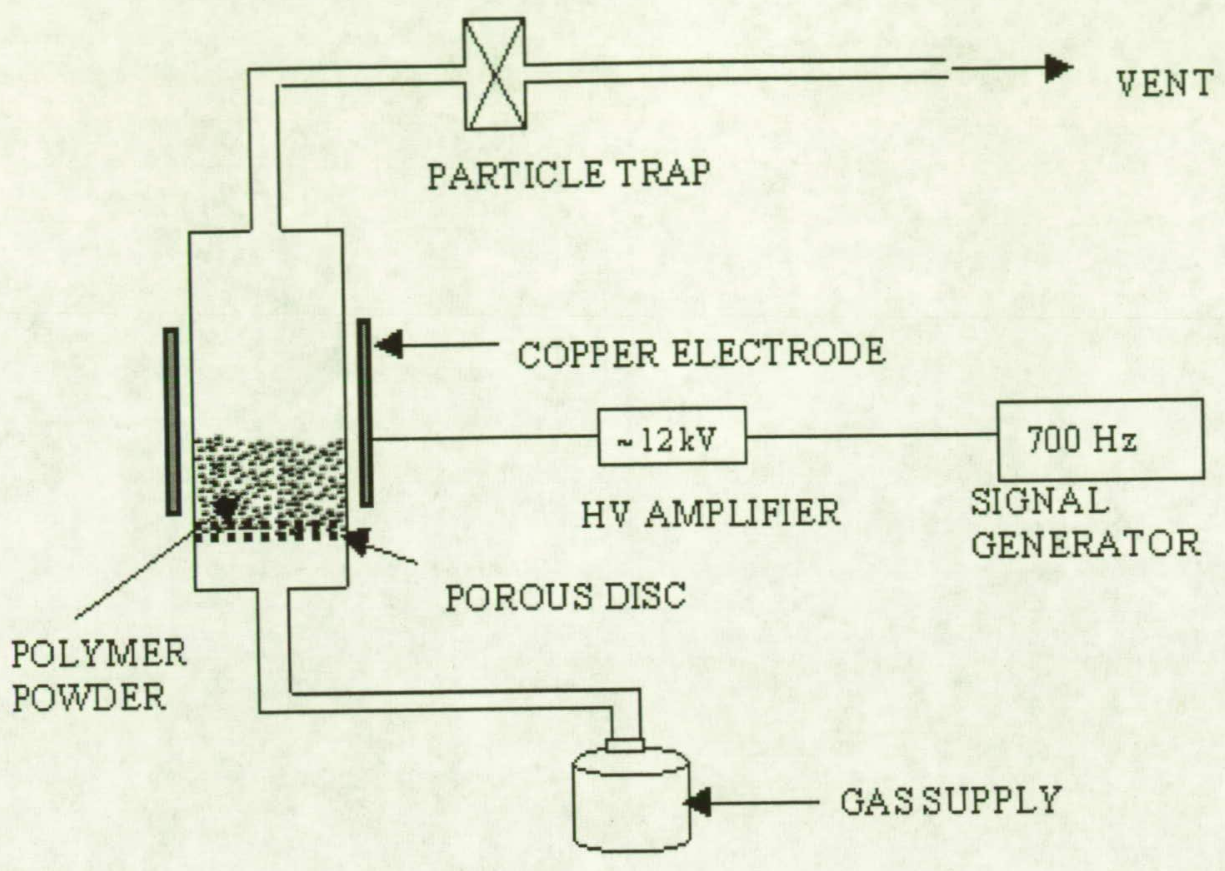

FIG. 19 


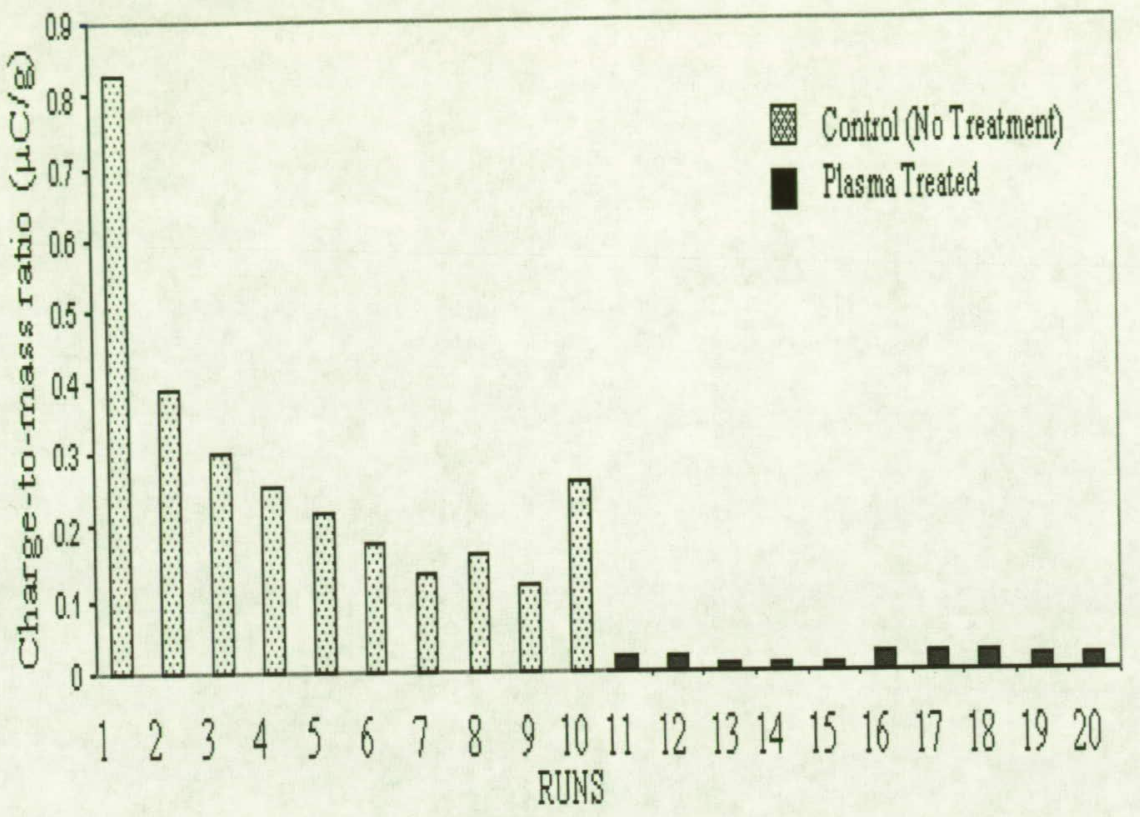

$F \mid G .20$ 